Free version (available until July 21 2017): https://authors.elsevier.com/a/1V8eM4s9Hvq71P

Permament online link: http://www.sciencedirect.com/science/article/pii/S1364032117308377

DOI: 10.1016/j.rser.2017.05.201

\title{
Challenges and trends of energy storage expansion planning for flexibility provision in low-carbon power systems - a review
}

\author{
J. Haas ${ }^{\mathrm{a}, \mathrm{b}, *}$, F. Cebulla ${ }^{\mathrm{c}}$, K. Cao ${ }^{\mathrm{c}}$, W. Nowak ${ }^{\mathrm{a}}$, R. Palma-Behnke ${ }^{\mathrm{b}}$, C. Rahmann ${ }^{\mathrm{b}}$, P. Mancarella ${ }^{\mathrm{d}, \mathrm{e}}$ \\ ${ }^{a}$ Department of Stochastic Simulation and Safety Research for Hydrosystems (IWS/SC SimTech), University of Stuttgart, Germany \\ ${ }^{b}$ Energy Center, Department of Electrical Engineering, University of Chile, Chile \\ ${ }^{c}$ Department of System Analysis and Technology Assessment, Instiute of Engineering Thermodynamics, DLR, University of Stuttgart, Germany \\ ${ }^{d}$ School of Electrical and Electronic Engineering, The University of Manchester, UK \\ ${ }^{e}$ Department of Electrical and Electronic Engineering, The University of Melbourne, Australia \\ *Corresponding author. jannik.haas@iws.uni-stuttgart.de, Pfaffenwaldring 5A, 70569 Stuttgart, Germany
}

\begin{abstract}
Expansion planning models are often used to support investment decisions in the power sector. Towards the massive insertion of renewable energy sources, expansion planning of energy storage systems (SEP - Storage Expansion Planning) is becoming more popular. However, to date, there is no clear overview of the available SEP models in the literature. To shed light on the existing approaches, this review paper presents a broad classification of SEP, which is used to analyze a database of about 90 publications to identify trends and challenges. The trends we found are that while SEP was born more than four decades ago, only in the last five years increasing research efforts were put into the topic. The planning has evolved from adequacy criteria to broader targets, such as direct costs, mitigation of $\mathrm{CO}_{2}$ emissions, and renewable integration. The modeling of the network, power system, energy storage systems (ESS), and time resolution are becoming more detailed. Uncertainty is often considered and the solution methods are still very diverse. As outstanding challenges, we found that (1) the large diversity of ESS, in contrast to conventional generation technologies, and (2) the complex lifetime and efficiency functions need to be addressed in the models. (3) Only a high temporal and spatial resolution will allow for dimensioning the challenge of integrating renewables and the role of ESS. (4) Although the value of ESS lies beyond shifting energy in time, current SEP is mostly blind to other system services. (5) Today, many flexibility options are available, but they are often assessed separately. In the same line, although cross-sectorial (power, heat, transport, water) SEP is becoming more frequent, there are many open tasks towards an integrated coordination. The planning of future energy systems will be multi-sectorial and multi-objective, consider the multi-services of ESS, and will inherently require interdisciplinary efforts.
\end{abstract}

\section{Keywords}

Energy storage expansion planning

Energy storage systems

Optimization models for power system planning

Investment decision support

Operational flexibility for low-carbon power systems

Variable renewable energy generation integration 


\section{Contents}

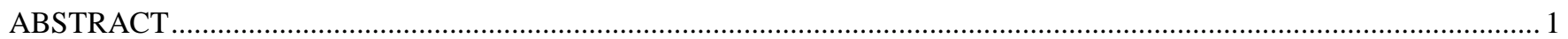

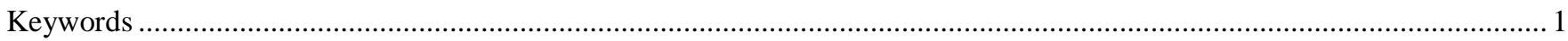

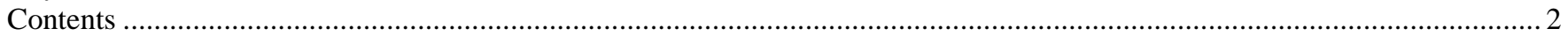

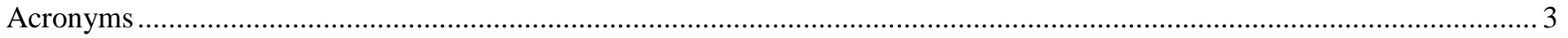

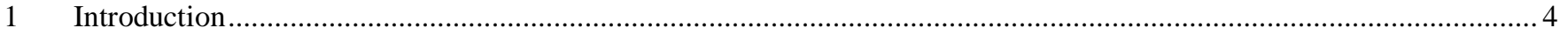

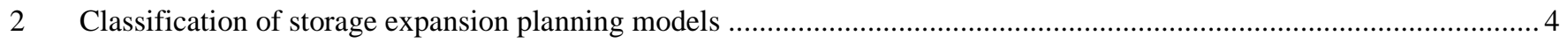

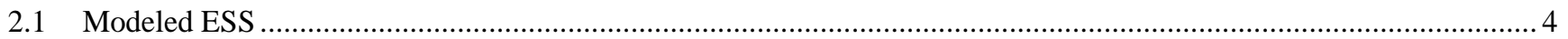

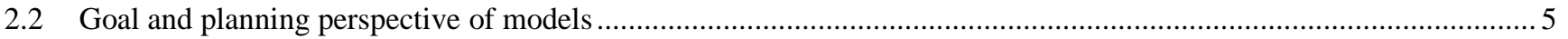

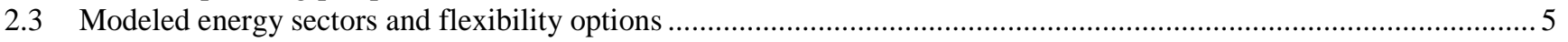

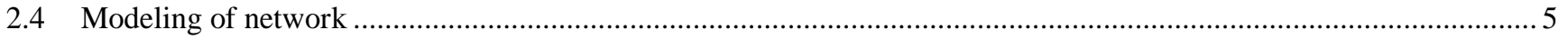

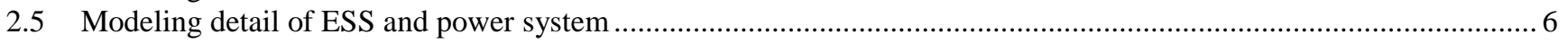

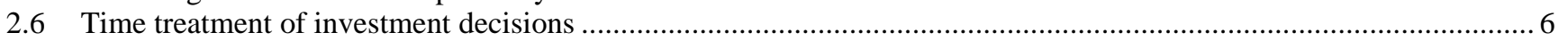

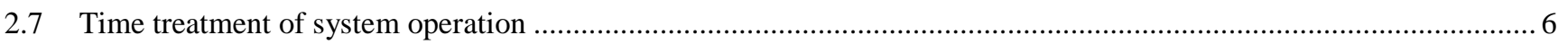

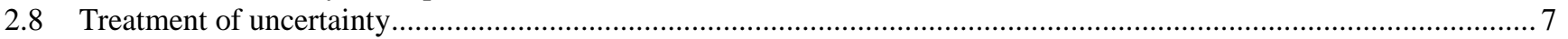

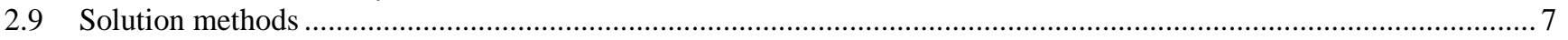

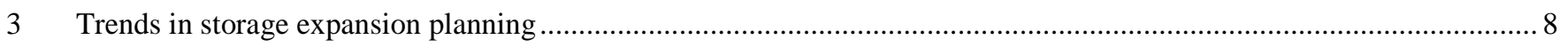

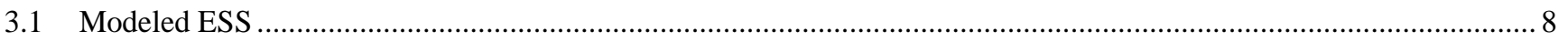

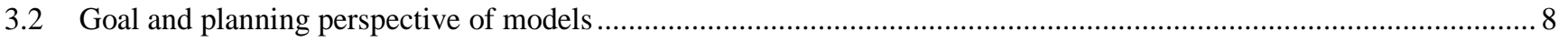

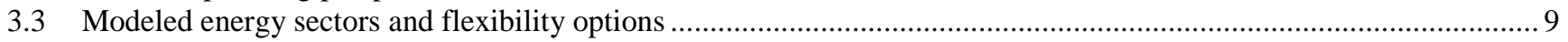

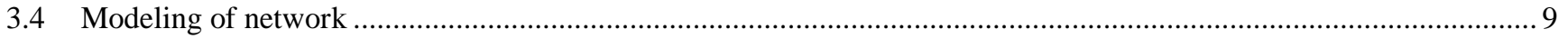

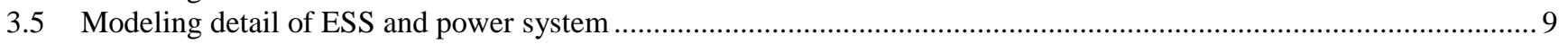

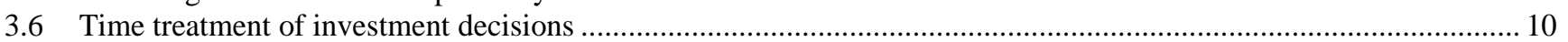

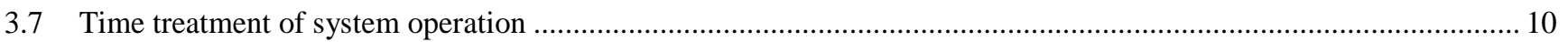

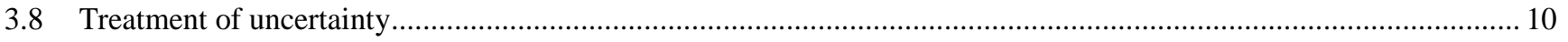

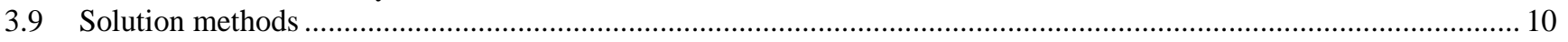

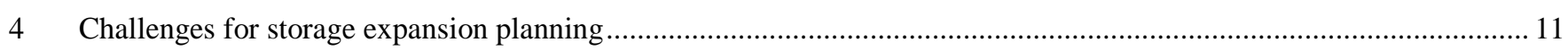

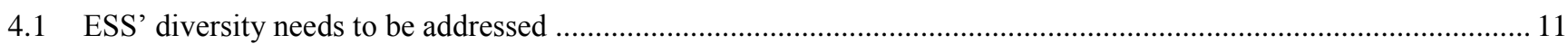

4.2 ESS' complex lifetime and efficiency functions need to be modeled................................................................... 11

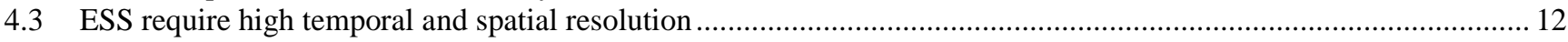

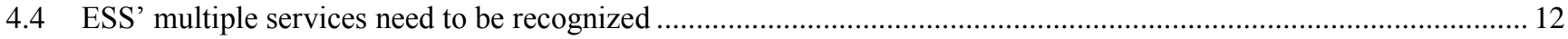

4.5 ESS' presence in many energy sectors require multi-sectoral approaches to be extended ......................................... 12

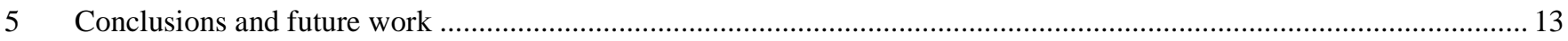

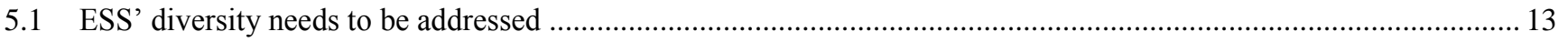

5.2 ESS' complex lifetime and efficiency functions need to be modeled....................................................................... 13

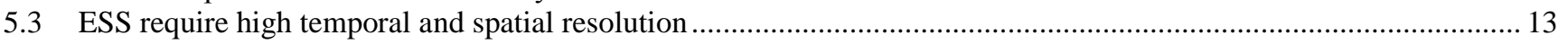

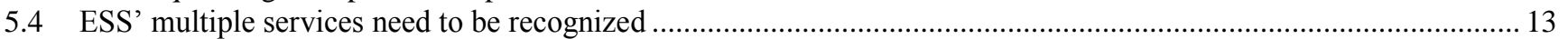

5.5 ESS' presence in many energy sectors require multi-sectoral approaches to be extended ......................................... 13

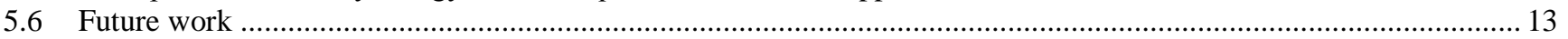

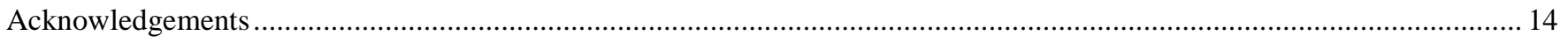

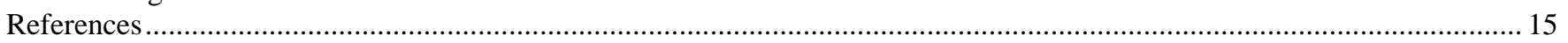

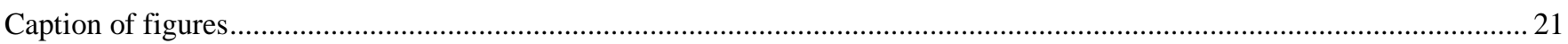




\section{Acronyms}

AC Alternating current

BESS Battery energy storage systems

CAES Compressed air energy systems

CAP Capacitors

CHP Combined heat and power

CSP Concentrated solar power plants

DC Direct current

DSM Demand-side management

DW Drinking water installations

EL Electrolyzers

ESS Energy storage systems

EV Electric vehicles

FC Fuel cells

FW Flywheels

G Generic storage

GEP Generation expansion planning

GT Gas turbines

$\mathrm{H}_{2} \quad$ Hydrogen

HT Heat technologies

LP Linear Programming

MILP Mixed Integer Linear Programming

MINLP Mixed Integer Nonlinear Programming

NLP Nonlinear Programming

P2G Power to gas

PHS Pumped hydro storage

PV Photovoltaic

SEP Storage expansion planning

vRES Variable renewable energy sources

WR Water reservoirs 


\section{Introduction}

Worldwide population growth, the greenhouse effect, and sustainable policies demand an increasing use of renewable energy sources around the world. Indeed, the deployment of wind, solar and hydropower resources has been remarkable and is still rising [1]. However, integrating such massive amounts of variable renewable energy sources (vRES) into power systems poses several technical and economic challenges. In particular, vRES are difficult to predict and deliver a highly fluctuating power output [2], thus adding uncertainty and variability to the planning and operation of power systems. Moreover, the potential of vRES is usually spatially distributed and rarely correlates in time with the load profiles. These characteristics of vRES challenge the power system's adequacy (energy and power balance) and voltage and frequency regulation [3]. Thus, in order to successfully integrate large shares of vRES, the planning and operation of power systems need to become more flexible than they are today [4-7].

The required flexibility can be provided through several approaches (see Fig. 1). These include operational strategies (e.g. energy curtailment [8], power output controls [9-12], more frequent dispatches [13], industrial and residential demand-side management (DSM) [14]), new market structures, and integration between different energy vectors such as the heat, transport and power sectors [15-18]. Alternatively, one can modify the power system infrastructure by reinforcing the transmission infrastructure [19,20], adding flexible generation technologies (e.g. gas turbines) [21,22], and energy storage systems (ESS) [23,24].

Particularly, ESS are widely esteemed as potential solutions for high shares of vRES [25-27]. The available ESS technologies (e.g. batteries, pumped hydro storage and hydrogen) differ vastly in terms of investment costs per power capacity and per energy capacity, lifetime, storage losses, efficiency, ramping rates and reaction times [23,25,28]. Moreover, current research concludes that there is no single ideal -or even supreme- ESS technology [24,25,28-30]. Indeed, the requirements for ESS depend on the characteristics of the power system under study and on the characteristics of the vRES. Consequently, the key question is: what combination of storage technologies is needed to tackle the challenges of vRES integration?

Expansion planning [31] is conventionally used to deal with this kind of questions. For example, generation expansion planning (GEP) [32-34] determines an optimal investment plan for generation capacities during a given study horizon. Its goal is to serve the energy demand while satisfying a set of economic and technical constraints. GEP is frequently employed by policy and decision makers to decide when and in which generation technology to invest. Depending on the decision variables, energy expansion approaches can traditionally be classified into generation expansion planning [35] and transmission expansion planning [36,37]. When the focus is put on investment decisions of ESS, we refer to it as storage expansion planning (SEP). In practice, generation, transmission, and storage can also be planned jointly [38,39].

Many research and review papers about expansion planning of the energy sector can be found in the literature, including power generation [40,41], power transmission [37,42,43], and gas- and power-transmission [44]. A comprehensive review of the available GEP software is shown in [45] and [46]. However, reviews about SEP remain scarce. Our paper aims to fill this gap.

This review makes three contributions to the existing literature. First, it provides a clear classification and overview of SEP models. We analyze the modeled ESS, energy sectors and flexibility options, the planning goal, the modeling detail of the systems, the time treatment of the investment and operational decisions, the consideration of uncertainty, and the solution methods. Second, we identify trends in how current SEP literature evolves in dealing with these aspects. Third, by contrasting newer SEP approaches to conventional GEP, we outline the challenges of planning ESS expansion. In these challenges, we focus on the diversity of ESS, the lifetime and efficiency functions of ESS, the required temporal and spatial resolution for an adequate modeling of ESS, the multiple services ESS can provide, and the inter-sectoral coupling through ESS.

The remainder of this paper is structured as follows. Section 2 provides a classification of models for SEP. Section 3 analyses the trends of ESS investment planning, while Section 4 identifies the remaining challenges. Finally, Section 5 presents the conclusions and recommendations for future work on SEP.

\section{Classification of storage expansion planning models}

Similarly to GEP, SEP considers the total costs of the system, given by operational and investment decisions over a time horizon of typically 10-30 years. Its most basic version is an energy balance that matches (e.g. yearly) generation with demand assisted by the use of ESS.

The planning models for ESS have evolved in time. However, current approaches still make strong simplifications when compared to real systems. Thus, we classify existing SEP can be classified according to their abstraction level: (1) considered ESS, (2) goal and planning perspective of models, (3) considered energy sectors and flexibility options, (4) network modeling, (5) detail of power system and ESS, (6) time treatment of investment decisions and (7) of system operation, (8) treatment of uncertainty, and (9) solution methods for the resulting model. This classification is explained in more detail in Sections 2.1 to 0.

\subsection{Modeled ESS}

SEP can be classified according to the types of ESS and the number of different ESS that are taken into account in the planning process. ESS types can again be classified based on their storage capacity, spatial distribution, and mobility.

First, according to their storage capacity, it is possible to divide ESS into short-term and long-term systems (although to date there is no consensus in the literature about a clear limit). Reference [47] considers short-term storage to have an energy capacity from seconds to days, such as flywheels (FW), capacitors (CAP), battery energy storage systems (BESS) and molten salts (in concentrated solar power plants - CSP) and compressed air energy systems (CAES). The same reference considers long-term

(C) 2017. This manuscript version is made available under the CC-BY-NC-ND 4.0 license http://creativecommons.org/licenses/by-nc-nd/4.0/ 
systems to have an energy capacity from weeks to seasons, such as water reservoirs (WR) and gas or hydrogen (H2) storage. Pumped hydro storage (PHS) and heat storage, depending on their size, can serve both the short- or the long-term [47]. CAP and FW have particularly low energy capacities and are suited for high-power applications up to 10 seconds. Consequently, CAP and FW are commonly not considered in SEP.

Second, ESS can be grouped in centralized and distributed systems. The former includes large installations, such as PHS, while the latter refers to modular units such as home-batteries in combination with roof-top photovoltaic (PV) systems [47].

The third and last criterion considers their mobility. Systems fixed to one location comprehend most of the centralized and many of the distributed ESS [47]. Mobile storage is given mainly by electric vehicles (EV) or gas trucks, all of which are distributed ESS.

The number of considered ESS types allows classifying SEP into single- or multi-storage approaches. In contrast to the former, multi-storage SEP can detect the synergies between different ESS systems.

\subsection{Goal and planning perspective of models}

In SEP, a cost minimization is usually applied by central planners (e.g. vertically integrated power companies) or policy makers (of a government or group of nations) as opposed to the benefit maximization of private investors [48]. Central planners rely on a cost minimization formulation and consider the expansion of a whole region. Private companies decide investments in their areas based on the energy price projections of the remaining system. When every private company tries to maximize its benefit, both planning perspectives (central and private) should lead to the same outcome, under perfect market competition, and without transmission constraints. However, real markets are rarely perfect, provoking differences, for which agent-based models can be used [49]. Nevertheless, the existence of complex markets and distortions does not mean that central planning has become obsolete. On the contrary: the result of central planning is commonly used as a benchmark for measuring the health of the system and for identifying the required corrective actions to be taken by policy makers [50]. Especially when planning a long-ranging horizon, the market may be of secondary importance as it is highly dynamic and can adapt accordingly.

The target of SEP (i.e. the objective function of the resulting optimization problem) can be economic as a cost minimization or benefit maximization [51-55]. But many more dimensions play a role in the SEP decision-making process [56], such as $\mathrm{CO}_{2}$ emission reduction in terms of maximum targets or penalties [22,57], robustness of the system [58] and resilience of the system, e.g. to climate change. If not all targets can be translated into economic units, the problem becomes multi-objective $[59,60]$.

\subsection{Modeled energy sectors and flexibility options}

Depending on the sectors considered, the existing SEP approaches can be divided into electricity models and (multi-sectorial) energy models (see Fig. 2). In the latter, different forms of coupling between the heat, transport, gas and water sectors are taken into account.

In the general context of future multi-energy systems [18], the electricity and heat sector are coupled through combined heat and power (CHP) plants, as well as cooling and heat power plants (when also adding cooling) [61], and in general in distributed multi-generation plants $[62,63]$. These couplings bring virtual electricity storage options through the possibility to operate CHP plants flexibly[17,64], especially in the presence of thermal storage and/or energy vector substitution options [65,66], as well as through building heating and process heat $[17,64]$. Other heat storage technologies (HT), especially in the presence of buffers for heat pumps and domestic hot water tanks, can offer additional storage options.

Other energy vectors can provide important forms of flexibility to the power system. For example, sectoral interactions between power and transport clearly involve EV, powered by fuel cells (FC) or batteries, which are per se a form of mobile storage $[67,68]$.

Further, there are various couplings that emerge when considering a joint operation of the electricity and gas networks [69,70]. In particular, the Power-to-Gas (P2G) technology represents an ESS option that arises from this electricity-gas interaction. Namely, P2G allows production of $\mathrm{H}_{2}$ via electrolyzers (EL) that can later be used by FC in the power and transport sector or by gas turbines (GT) in the heat and power sector [71]. Also, there may be P2G options to inject hydrogen (as well as synthetic natural gas), produced from otherwise curtailed renewable electricity, into the gas network, which is effectively used as a means of daily [69] or seasonal [72] storage of clean energy.

Focusing on storage interactions, the water and electricity sectors are coupled by water reservoirs, whose multiple purposes (e.g. irrigation, ecological services [73]) usually imply a more constrained operation when using those also as electricity storage resource. However, even in such more constrained cases, technical solutions exist, such as installing after-bays (with/without pumping capacity) that may offer direct/indirect storage options to the electricity sector [74]. Also drinking water installations (DW) couple both sectors, for example emerging desalination plants can use the obtained brines to generate electricity when equipped with an additional turbine [75].

Within the electricity sector, it should be made clear that ESS are not the only source of flexibility for vRES integration. It is important to plan ESS options jointly with other options for maximizing the opportunities of storage and the benefits of the whole system, e.g. ESS and flexible generation [76], ESS and transmission ${ }^{1}$ [39], ESS and energy curtailment options [77], and ESS and multi-generation systems $[65,78]$.

\section{$2.4 \quad$ Modeling of network}

The detail of modeling the power network is relevant to identify transmission constraints and local potentials. Existing approaches range between one-node (also known as copper-plate models) and multi-node models of the grid.

\footnotetext{
${ }^{1}$ Expansion planning of transmission infrastructure is a flexibility option, which is different to modeling the existing grid as explained in Section 2.4 .
} 
When harnessing local potentials of vRES (e.g. wind power from remote offshore areas or solar power from distant deserts) or of ESS (e.g. PHS in the mountains or $\mathrm{H}_{2}$ in caverns), it becomes relevant capturing their spatial dimension. Although one-node approaches can still model these local potentials (e.g. by modeling them as different technologies, each with a different expansion capacity, energy profile, cost, and yield), these are reasonable only if transmission capacity is not an issue. If transmission congestions (bottlenecks) do exist, multi-node approaches should be applied.

Multi-node models apply different approaches for taking into account power exchange between regions. First, the simplest case is a traditional transport model, where each line has a maximum transmission capacity. Other parameters such as voltage and phase angle are not considered. Second, a more detailed approach is offered by direct current (DC) models. These consider current balances (Kirchhoff's law) to find the power flows in the network [79]. To keep DC models linear, transmission losses are usually neglected or simplified, for instance, in the form of a fixed proportion of transmitted energy or, alternatively, modeled by piecewise linear functions [80]. Besides, their linearity is in accordance to many of the transmission pricing models [79]. Third and last, alternating current models (AC) additionally include voltage equations, but the computational burden may be prohibitive (nonlinear models, iterative solving schemes, long solving times) for larger systems [81,82].

Given the trade-off between computing time and precision in modeling high voltage networks, transport models are a commonly used approximation for direct current power lines; and DC models are often used for alternating current grids [79]. The use of AC models is indispensable when voltage constraints need to be studied explicitly, such as SEP in (low-voltage) distribution grids.

\subsection{Modeling detail of ESS and power system}

ESS can be modeled with different degrees of detail. Basic parameters involve their power capacity (in MW) and energy capacity (in MWh). Those capacities might remain constant in time or decrease due to aging. Some ESS have different capacities for charging and discharging, e.g. PHS, in which the converter (turbine) and charger (pump) may be physically different units. The efficiency can be considered constant or variable as a function of their state of charge, state of health (aging), operating temperature and dis/charging speed. Self-discharge might also be modeled.

Also, the power system is often simplified in SEP. Models range from a set of simple energy balance equations $[52,83]$ up to complex formulations describing technical constraints of generators and power reserve requirements [84].

Energy balance approaches may involve simple spreadsheet balances that add up the expected energy to be generated during, say, a year, aiming to match demand. The screening curve approach [34] allows through graphical inspection finding the optimal generation mix based on the peak-load-pricing theory [85]. These curves compare the structure of demand (in terms of a load duration curve) with investment and operational costs of the generation and storage technologies. Energy balance models based on optimization can also be found. Here, the load is commonly simplified in the form of discretized time blocks [86], for which the best solution found is a mix of generation and storage technologies that is able to supply energy to all time blocks.

Advancing in the level of detail of SEP models, reliability indices can be considered such as expected energy not served (EENS) [87,88] or loss of load probability or expectation (LOLP/LOLE) [55,86]). Technical constraints important for scheduling the operation of the generation units (unit commitment - UC) can also be included. These involve minimum online/offline times, startup and shutdown times, up/down ramps, and minimum power outputs, among others [84]. Further constraints may involve system operation in terms of operational reserve (e.g. spinning reserves) $[84,89]$ and proxies for frequency support $[90,91]$ and voltage support $[92,93]$.

In practice, when the focus of research is on macroeconomic balances, simple top-down formulations are used. These are usually energy-based models, available in software packages such as LEAP [94], MARKAL [95], ENPEP [96] or NEMS [97]. Conversely, bottom-up models target a high technical detail, for which complex formulations (e.g. reliability, unit commitment) as in HOMER [98], EnergyPLAN [99] and PLEXOS [100] are chosen.

\subsection{Time treatment of investment decisions}

The time treatment of investment decisions in expansion planning can be classified in static and dynamic approaches (see Fig. 3). Static methods calculate the expansion decisions (answering to "where and how much") at the end of a given time horizon [57,101]. Dynamic methods additionally optimize the entry year of new investments (responding to "when"), also called the expansion path. This is considered to be more useful in practice but comes at the cost of solving times [36,102]. A combination of both approaches is to use milestone-years. Here, a static optimization is performed every five years, for example [103]. Sometimes, the results (generation capacity mix) are used as input for computing the next milestone-year [104]. The rolling horizon approach $[105,106]$ follows that logic by splitting the planning horizon into smaller and overlapping periods which are solved sequentially. For example, a common setting in long-term studies is to choose a set of 10-year planning horizons with 5 years of overlap. In contrast to milestone-years, each period is dynamic. Milestone-year and rolling-over approaches optimize each period individually, which reduces the complexity of the optimization problem at the cost of being short-sighted (myopic).

\subsection{Time treatment of system operation}

SEP can be divided, depending on how they treat the time dimension of the system operation, in sequential (also called chronological) and non-sequential approaches. This distinction is closely related to the modeling detail of ESS and the power system (Section 2.5).

Non-sequential approaches include the energy balances approaches (simple balances [83], screening curves [85] and load duration curves [86]). These neglect technical constraints from the system, such as ecological flow limits of hydropower, on/offline times of conventional generators, and state of charge and state of health for ESS. The neglected effects are, if at all, incorporated in ex-post studies. Hence, in practice, the found solution might be infeasible or more costly (suboptimal).

(C) 2017. This manuscript version is made available under the CC-BY-NC-ND 4.0 license http://creativecommons.org/licenses/by-nc-nd/4.0/ 
Instead, chronologic or sequential approaches can model the temporal interdependencies. These are particularly critical in small or isolated power systems with low inertia levels and poor frequency control capabilities [107].

Other approaches of SEP consider type-days or type-weeks to approximate chronologic formulations by sampling a few representative days or weeks of the year [84,93]. The selection process of type-days or type-weeks might include clustering methods for scenario reduction $[84,108,109]$. Some of the type-days/weeks are chronologic, while others are based on (nonsequential) load duration curves. However, none of them can capture the operation beyond their horizon (day/week).

All approaches can vary their time resolution. Frequently, hourly up to multi-hourly time steps are observed. Some approaches use heterogeneous time steps aiming to find a good representation of the load curve with a few time steps. Coarse scales allow solving larger systems, in trade-off with the operational model's accuracy.

\section{$2.8 \quad$ Treatment of uncertainty}

Uncertainties can be classified according to their nature in rational and stochastic [110]. Rational uncertainty arises when trying to anticipate the strategic behavior of agents (suppliers, customers, traders, and regulators) in market competition and is usually addressed with game theory models [49]. Stochastic uncertainties arise from random influences such as weather, load, resource availability, energy and technology prices. Instead of looking for an (deterministic) optimum under allegedly known conditions, stochastic uncertainties can be handled by optimizing an expected value, minimizing the regret, or keeping probabilities of undesired events (e.g. unserved energy) below a given threshold [111]. References [112,113] show an overview of stochastic models applied to general energy planning, while references [114], [108] and [115] show examples of SEP models that include the stochasticity of prices, load, and vRES. Stochastic optimization may also be useful for flexible expansion planning when decisions consider the potential resolution of uncertainty in time and the possibility of adjusting decisions based on such resolution [78].

Another valuable option to account for uncertainties is the Monte-Carlo simulation, which runs deterministic models numerous times under randomized conditions to attain probability distributions $[60,64,87,92]$. When quantification of uncertainty is particularly difficult, scenario analysis (a manually chosen set of possible parameter outcomes) is performed. As a general rule, considering uncertainties multiplies the required solving time by a substantial factor, at least by the number of scenarios or MonteCarlo repetitions.

\subsection{Solution methods}

SEP is frequently formulated as a mathematical optimization (or mathematical programming) problem. However, many other decision support methods are found in the literature.

Optimization problems can be divided according to their linearity into two groups. First, Linear Programming (LP) is comprised of the problems with a linear objective function and linear constraints [116]. If some variables can only be integers, the problem is called Mixed Integer Linear Programming (MILP) [116]. The second category of problems is Nonlinear Programming (NLP), which has nonlinearities in their objective function and/or constraints [116]. Again, if some variables can only be integers, the problem becomes a Mixed Integer Nonlinear Programming (MINLP) [116]. Although there are many more subtypes of NLP problems, frequent approaches used in the energy sector include Quadratic Programming [117] (with a quadratic term in the objective function) and Quadratically Constrained Programming (with quadratic constraints) [109].

To solve mathematical programming problems, there are many solution methods available. Commonly used exact solution methods include Simplex or Interior Point for LP, Branch and Bound for MILP, QP-simplex for Quadratic Programming or Barrier for Cone Programming. When a limited computing capacity hinders these algorithms to find the optimal solution in a reasonable time, decomposition techniques can be applied in order to shrink the problem. Examples are Dynamic Programming [118], Benders decomposition [119] and Danzig-Wolfe [111]. They aim to find the same exact optimum, but they can be faster as they split the global problem into smartly chosen coupled subproblems.

When the above methods fail to find the optimum in a prudent time (usually in NLP), heuristics come into play. They trade precision for speed, aiming to find a good solution in a feasible time rather than searching for the global optimum. Examples of heuristics are Artificial Neural Networks [120], Genetic Algorithms [121], Tabu Search, Particle Swarm methods [122], Ant Colony approaches, and so forth [123]. Reference [124] studies their performance in traditional GEP, whereas reference [123] analyzed some of them in SEP. Additional advantages of heuristics are that many offer options for parallel computing and are robust against missing and noisy data [125].

Other decision support methods for SEP rely on control rules [93], energy accounting frameworks [83,126,127] or time series analysis [21,128]. As no standard name for this kind of problems could be found in the literature, these models will be called other solution methods in the remainder of this review.

Finally, some models are hybrids as they combine several of the approaches mentioned above. These split the problem into one for the investment decisions and another for the operation decisions (although they follow the logic of mathematical decomposition techniques, they are heuristics). For example, reference [121] formulates the investment decisions of ESS as LP (solved with Simplex) and the operational decisions as a set of control strategies (that then feed the operational costs back to the investment problem). It is also frequent to observe hybrid approaches that combine top-down (macroeconomic) with bottom-up (technical) models (see Section 2.5) [129,130].

In general, the used modeling detail is a compromise between the required accuracy and computing limitations. For that reason, the treatment of ESS is often simplified. Similarly to GEP, detailed technical tools as ex-post analysis for checking the operational feasibility are also used in SEP, especially in the presence of large shares of both vRES and ESS.

References [131-133] provide an exhaustive review of optimization methods applied to renewable energy and energy planning. 


\section{Trends in storage expansion planning}

In this Section, we identify the trends in SEP. For this, we collected a set of journal papers related to the topic, which we then classified using the criteria mentioned in the previous Section. The database was set up with all journal papers that are indexed by Google Scholar, published online before 2016, and contained both the words "energy" and "storage", and "expansion" and/or "planning" in their title. Particularly, in the first years of SEP (1970-1999), only a few results were found, which is why the reference list of each paper was checked for further publications. Only for this period, conference proceedings were also included due to the lack of online material. For the remaining decades, further references to those found by the above search criteria were added, aiming to evaluate as many related studies as possible. The found papers were skimmed and those which did not provide sizing of ESS were discarded. In total, 87 papers were analyzed in depth, as shown in Table $1[17,22,27,49,51-$ $55,57,58,60,64,67,68,71,72,75-78,83-93,101,103,108,109,120-123,126-129,134-176]$. The overview of the resulting analysis can be found in Table 2 .

The first 30 years (1970-1999) of SEP show only 13 publications, whereas the 2000s account for another 14. In the 2010s, SEP takes off: 60 studies are found until the end of 2015. The remainder of this Section will analyze the found trends of SEP based on the classification criteria of Section 2.

Table 1

\begin{tabular}{cc} 
Number of SEP publications found per decade \\
\hline Decade & Publications \\
\hline Earlier & 8 \\
$1990 \mathrm{~s}$ & 5 \\
$2000 \mathrm{~s}$ & 14 \\
$2010 \mathrm{~s}$ & 60 \\
Total & 87 \\
\hline
\end{tabular}

\subsection{Modeled ESS}

The need for energy storage is not new. In the beginning of power systems, operational flexibility was given by fossil power plants that stored their energy in the form of primary energy, mainly gas and petrol in tanks, and coal on adjacent yards. As long as that storage capacity is large enough (not imposing active constraints on the system), there is no need for modeling it. So, it comes as no surprise that SEP is born in the context of a more restricted primary energy source: hydropower reservoirs.

The geographic development of SEP is illustrated in Fig. 4; whereas the technologies considered are shown in Fig. $5^{2}$. SEP is first performed in the '70s in the USA and Canada [139,141], although the first PHS installations already appeared in the 1890s in Italy and Switzerland [177]. During the following decade, Japan [52,53] and South Korea [54] join the topic, while the USA $[51,86]$ keeps on adding publications. Also, Denmark appears, envisioning the role of storage for a Nordic "wind-hydro" system [166]. Mainly WR and PHS are sized, then first models for generic (G) storage emerge. During the 1990s, storage planning goes beyond the traditional hydropower nations. For instance, the first publications from Egypt and Libya show interest for PHS [55], while research elsewhere starts to look at a broader variety of ESS, including BESS [161], CAES, CAP and FW [126]. Also, the first cross-sectorial models appear with the joint heat-power planning of heat tanks [148]. In the 2000s, SEP becomes a worldwide topic and more studies focus on these emerging technologies, as well as on CHP [64,154] and EV [67,68]. The technology spectrum continues to grow in the 2010s, adding $\mathrm{H}_{2}$ with a focus on P2G [71,72,174] and CSP [140]. Particularly, the BESS family receives attention with focus on developing technologies, such as Lithium-ion (Li-ion) [49,127,164], sodium-sulfur (NaS) batteries [127,164], and flow batteries [49,91,120,127].

Although diverse ESS are included in SEP over the decades, before the 2000s the focus is on one technology at a time. This changes in 2004, when Barton [93] introduces a simple spreadsheet to find short- and mid-term storage for a wind farm. The first optimization models that include multi-storage options appear as recent as 2014 [89,121,164]. Only a handful of studies analyzes more than two ESS at the same time. For example, reference [164] studies a combination of three ESS for a copperplate system, while reference [89] does the same for micro-grids. Bussar et al. [121] are the first ones to address multi-storage needs for a spatially distributed system: Europe-Middle East-North Africa with a 21-node resolution. One year later, Zerrahn et al. [174] focus on a storage mix with reserve constraints. Understanding such optimal ESS mixes will only become more relevant on the way to low-carbon power systems.

\subsection{Goal and planning perspective of models}

The planning goals of SEP have evolved in time. The overview and evolution of planning targets are given in Fig. 6. At first, cost and adequacy are the ruling planning criteria. During the 2000s, with rising concerns about climate change, the first SEP studies including $\mathrm{CO}_{2}$ emission targets appear $[64,68,93,169]$. Nowadays, $\mathrm{CO}_{2}$ targets or emission penalties are common criteria in SEP $[22,39,57,85,101,140]$. The increasing conviction towards green power as a solution for emission mitigation pushed many studies to include RES integration goals, in terms of minimizing energy curtailment or maximizing possible RES shares $[27,120,121,160,167,172]$, although cost criteria are naturally still frequent.

An important goal, but often neglected in the planning stage, is the reliability and security of supply that storage can provide. Recent relevant work in this regard [178] (but without sizing ESS) assesses the contribution of ESS to the adequacy of supply and

\footnotetext{
${ }^{2}$ In these kinds of figures, the y-axis shows the number of SEP publications that match a given criteria relative to the total number of SEP publications of a given decade. If a given criteria allows multiple answers, the y-axis becomes relative to the total number of answers of a given decade.
}

(C) 2017. This manuscript version is made available under the CC-BY-NC-ND 4.0 license http://creativecommons.org/licenses/by-nc-nd/4.0/ 
the ability of DSM and ESS to displace conventional generation. Reference [179] defines the latter point formally in terms of capacity credit of ESS.

The existence of diverse optimization goals has led to multi-objective formulations in many disciplines. In SEP, however, single-objective approaches are prevailing with only a few exceptions during the 2010s (e.g. [60,162]). The remaining studies focus on expressing their targets in a common (monetary) dimension or including them as constraints or as scenarios (e.g. SEP for a scenario of $100 \%$ vRES).

Before 1990, SEP is performed solely from a central planning perspective. In the next twenty years, with the liberalization of the energy sector, several studies from a private perspective emerge, involving models for attaining the production cost of technologies $[83,126,144,149]$. However, centrally planned SEP has not become obsolete. In fact, the vast majority of models of the 2010s is still based on such a perspective.

\subsection{Modeled energy sectors and flexibility options}

Until 1996, SEP focused only on the electricity sector. Since then, cross-sectorial planning has arisen, as shown in Fig. 7. The heat sector is the first one to be considered in SEP, particularly exploiting flexibilities in the heat storage of CHP $[64,148,154]$. A joint power-heat SEP has become more relevant with time [67,134,135,143,151,153,156,158,159]. For example, down to the level of individual buildings, there are clear examples of ESS able to support DSM mechanisms and to provide flexibility. They exploit low-cost thermal storage available in the building material and hot water tanks [143] when coupled to micro-CHP or electric heat pumps. Other recent studies focus on the operation of heat ESS. They include the thermal inertia of buildings and aim to highlight that the benefits from virtual energy storage available in residential applications potentially need to be traded off against the user's comfort level [180]. On the thermal energy storage side, this is also stirring a number of discussions and publications on the appropriate level of complexity of building simulation tools to capture the available thermal inertia and impact on comfort level [181]. Reference [65] shows the importance of coordinating electricity and heat in district energy systems and the possibility of thermal storage to support the provision of flexibility.

Since the second half of the 2000s, also the transport sector starts to play an increasing role in SEP [67,68]. Consequently, it is becoming more frequent to assess the added value of coupling the transport-power-heat sectors $[67,151,153,159]$. Reference [159], for instance, shows an algorithm for demand response participation in distributed energy markets that considers both EV and heat pumps as key components to create flexibility and diversity in the demand side. Similarly, the coordination of storage in the transport-power-heat sector can be used to provide frequency services [182].

As a sector-connecting technology, P2G also shows increasing relevance in SEP $[71,72,145,174]$. Strictly speaking, these studies do not explicitly consider the gas sector, but model P2G only from the power sector point of view. Reference [72] is one of the few exceptions that models both the power and gas grid to study the benefits from P2G as seasonal storage. Another study [69], following that approach, focuses on the possibility of using P2G-based short-term storage to avoid electrical and/or gas network investment, even though no ESS sizing optimization is carried out.

With regards to the water sector (e.g. irrigation and drinking water supply) coupling, while its operation has been linked to the electricity sector for some decades $[119,183]$, investment decision coupling has started to emerge only recently. For example, reference [184] includes in SEP the water demand and price as well as water network constraints. Also, the increasing demand for water desalination plants has triggered interest to understand their ability in providing flexibility to the power sector, e.g. through a special kind of PHS based on the resulting brines of reverse osmosis $[75,155]$.

Within the power sector, joint expansion optimization of ESS and other flexibility options are frequently observed since the 2000s, e.g. ESS and transmission planning [92,101,121,137,140,151,168], and ESS planning with DSM options [22,27,67,181]. Energy curtailment $[64,77,108,144,176]$ and investments in flexible generation technologies $[76,103,129,140,144,168]$ are recurring flexibility choices in SEP, as well.

\subsection{Modeling of network}

The network modeling in SEP was strongly simplified for a long time. Indeed, studies before 2008 do not consider the transmission grid, with the exception of two papers $[154,166]$.

During the years, SEP shifts towards multi-node approaches, accounting now for approximately $50 \%$ of the studies of the present decade. Most of these studies model the transmission system with 5 up to 30 nodes. Among the multi-node studies, the most frequent approach to model the transmission system is via transport models [22,58,115,121,140,151] and DC power flows [57,72,90,137,173,175]. In SEP, the AC approach is limited to a few studies about distribution grids $[92,109,122,163]$.

Regarding the energy losses in transmission systems, only few data could be found in the revised publications. The authors who do indicate their approach recur to model the losses as a constant proportion of demand [166], as a variable amount computed by iterations [122], or as an endogenous variable represented by piece-wise linear approximations [175].

\subsection{Modeling detail of ESS and power system}

SEP models have gradually gained detail over the last decades (Fig. 8). The underlying equation of all studies is an energy balance, which in the simplest case is on an annual basis.

Before 1999, SEP is based on energy formulations only, with the exception of three publications that add reliability indices to their models $[51,55,86]$. The 2000s get interesting as the first SEP including UC formulations appear $[64,154,169]$. More detailed studies already include approximations for frequency [108] and voltage regulation [93]. In the 2010s, SEP approaches based only on energy balances still prevail. In absolute terms, formulations with UC [22,57,71,72,84,89,136,171,176], with reserves $[88,174,176]$, and with voltage $[92,109,122]$ and frequency $[90,91]$ regulation proxies are becoming widespread. However, their application is limited to about one-third of the studied publications. 
As for what concerns modeling of ESS, the vast majority of studies represents ESS by their energy and power capacity, and use a constant efficiency (roundtrip or dis/charge). A few exceptions use a variable efficiency, for example as a function of their state of charge [64] or their state and charge and operating current [91]. However, a variable efficiency in terms of their state of health or operating temperature has not been observed to date. Accounting for self-discharge is detected in some papers since 2013 [87,121,143,159,172]. Aging of the energy capacity and its effect on ESS lifetime is considered only in one publication [89].

Including a wide set of technical constraints of the power system, for example, reserves (primary, secondary and tertiary reserve) was long hampered by the involved computational efforts. Recently, it was demonstrated how linear programming approximations may be used to significantly decrease simulation speed with minimum loss of accuracy in UC models for relatively large systems, such as for Great Britain [185].

\subsection{Time treatment of investment decisions}

Due to the clear advantages of modeling expansion paths of investment decisions (precise evolution of the energy system, including the end of life of existing facilities, delays due to constructing times, etc.), one would expect the number of SEP with dynamic planning formulations to increase over the decades in accordance to advances in computing capacity. But this is not what happened (Fig. 9). Instead, in the beginnings of SEP (before 1990), 50\% of the models [53,54,86,139] had dynamic formulations, possibly conditioned by the long construction times of the main storage technologies of that time: hydropower reservoirs. Between 1990 and 2010, only two [168,169] out of 17 publications use a dynamic treatment for investment decisions. This trend is still valid today; about $10 \%$ of the publications target to find the expansion path of investments. In those approaches, the frequency of investment decisions (or milestone-years) has remained constant between one per year and one every five years.

\subsection{Time treatment of system operation}

Due to limited computing capacity, SEP traditionally used non-sequential formulations. Just in the 2000s, the shift towards chronologic models starts. Nowadays, about $90 \%$ of SEP studies focus on preserving the chronology, out of which $30 \%$ use sequential type-day/weeks approaches to capture time-dependent dynamics of ESS and vRES (Fig. 10).

The few non-sequential approaches that still remain usually correspond to particular research questions. For instance, one team aimed to make a gross economic evaluation for a wide spectrum of ESS, for which they only did a yearly balance (one time step) [127]. Others introduced a heuristic for sizing ESS relying on spectral analysis, which per definition interrupts the chronology [128]. Recently, screening curves were extended to SEP, which provide ease of solving the problem by graphical inspection, but again at the cost of the chronology [85]. Other non-sequential studies give up the chronology in trade of a longer planning horizon and a finer spatial resolution, e.g. reference [60].

Supported by advances in computing capacity and commercial solvers, time resolution in SEP has significantly improved over the last decades. Chronological models have increased their amount of time frames from about 10 in the beginnings of SEP, to 300 in the 1990s and 2000s, and to 8760 today. Furthermore, a year with hourly slices is the current standard, accounting for about $50 \%$ of the studies, even if this resolution usually requires spatially simplified systems.

\subsection{Treatment of uncertainty}

Most SEP models follow a deterministic formulation, of which some use scenario analysis to account for uncertainty. Other recurrent methods to study uncertainty in SEP include Monte Carlo simulation and stochastic optimization. Their evolution over time is shown in Fig. 11.

Modeling of uncertainties has been part of SEP since the 1970s when stochastic optimization was the preferred tool to account for stochasticity of load [54] and -surprisingly already- of renewable energy availability (water inflows) [86]. Although during the 1990s no stochastic publication is found, a decade later it becomes a fundamental part of SEP to model uncertain energy profiles [58,108,109,120,140,142,152,157,170,171,173] and uncertain expansion paths in time (multi-stage SEP) [78].

Scenario analysis emerges in the 1990s to add sensitivities of capital costs [148]. Since a decade later, $\mathrm{CO}_{2}$ emission prices [22,101,144], energy costs [83,150,158], vRES integration and maximum curtailment levels [77], and other technical parameters $[84,121,151,164,174]$ are the main variables studied through scenarios.

With growing computing power, Monte Carlo simulation arrived during the 2000s, being used mainly for vRES levels and forecasts errors [89,92,154], as well as for outages of generators [60,64,89]. During the 2010s, the use of Monte Carlo expanded to other technical parameters, such as reliability levels $[87,163]$ of the power system and efficiency parameters of ESS [57].

A recent publication relates to the liberalization of power markets. The emergence of trading agents has motivated SEP to include research based on game theory [49].

\subsection{Solution methods}

SEP has been formulated as mathematical optimization problems such as LP, MILP, NLP and MINLP, hybrid approaches and other simulation techniques (Fig. 12). These are then solved with corresponding algorithms.

Until 1999, many different approaches are found without any dominant one. For instance, SEP are expressed as LP [51,55,86], NLP [139,141,147] -including one MINLP [53]-, hybrids [54,148], and other decision support methods [126,161,166].

In the 2000s, LP [108,154,168,169], including MILP [138], displace nonlinear formulations. Hybrids and other solution methods, with a focus on production cost models $[83,144,149]$ and decision rules $[67,68,93]$ account for more than half of the publications of that decade.

During the 2010s, LP keeps being widely employed $[22,154,157,167,169,170]$ and are frequently run with commercial solvers based on Simplex or Branch and Bound. NLP has become more frequent again, especially for solving multi-node systems, which is concurrent with the proliferation of nonlinear optimization heuristics, such as Particle Swarms [122,163], Genetic 
Algorithms [123], Simulated Annealing [92], Artificial Neural Networks [120] and so on. A new popular approach includes time series analysis $[76,128,146]$.

In absolute terms, hybrids become more numerous. In SEP, these include i) optimizing the operation (with any of the above formulations) and through scenario inspection finding the optimal storage size [72,84,138,143,171]; and ii) optimizing the storage size, for which the operational costs are then attained by different methods (optimization or other solution methods) and fed back [121]. These approaches are in line with the fact that, given the complexity of future energy systems with increasing volumes of renewables, detailed simulations of power system operation will be more and more required in planning studies.

Motivated by the always limited computing capacity, model reduction techniques are applied to about a third of SEP publications. Decomposition approaches to reformulate the SEP into a master problem that determines the investments and a slave problem that calculates the operation, such as Dantzig-Wolfe [86] and Benders [51], emerge in SEP before 1990. Another early master-slave approach formulates the investment decisions as an optimal control problem and the operation decisions as an NLP [54]. Splitting the time horizon by means of Dynamic Programming corresponds to the earliest SEP publication found [139]. In the 2000s, the use of rolling horizons $[152,154]$ and phenomenological model reduction techniques (including fuzzy clustering of load [108] and grouping of generation technologies [169]) are approaches with positive effects on solving times, especially relevant in stochastic environments. During the last years, SEP publications appear about defining the number of nodes that should be modeled as a function of areas free of transmission bottlenecks [167]. Other studies focus on warm starting the optimization problem, i.e. by finding a good initial solution $[101,128]$.

\section{Challenges for storage expansion planning}

Research is consistent in that ESS will play a dominant role in vRES integration, as they can cope with the variability, uncertainty, and location-specificity of vRES. However, based on the findings of Section 3, in SEP several challenges arise in contrast to traditional expansion planning. These will be addressed as follows.

\subsection{ESS' diversity needs to be addressed}

In the review, we found that most of the studies represent ESS by using a handful of parameters (energy and power capacity, constant efficiency). However, there are other relevant and very dissimilar technical characteristics, which stand in great contrast with power generation plants. Some key features of ESS on this regard are reaction times, variable charge/discharge efficiency curves, operating/dead zones, variable lifetime, self-discharge and ramping capacity [25,28,104]. A short review of key characteristics of ESS and their main differences with conventional generators is explained as follows.

BESS may react to demand very quickly, providing high currents within seconds, and operate beyond their rated power (pulse rate capability). Their state of health, however, is strongly affected by cycling [25]. The lifetime expectancy does not only differ significantly between the different types of BESS but also within a certain family. For instance, the cycles of Li-ion batteries range between 200 and 8000 under standard testing conditions, depending on the manufacturer [186]. Curiously, sodium-sulfur batteries maintain their operating temperature mostly through charging and discharging cycles [187]. On the contrary, CAES is quite insensitive to cycling, offer low self-discharge rates, but have lower efficiencies. PHS can conveniently shift energy in the day/night horizon, while large WR can accumulate energy over the seasons. Both may assist in frequency control [19]. However, they also possess forbidden operating zones given mainly by their pumps [188]. Small regulation tanks of run-of-river power plants, up- and re-powering of hydro reservoirs, and conversion of reservoirs into pumping facilities can provide additional operational flexibility. Electrolyzers offer good cycling capabilities, due to high efficiencies at partial load. The attained $\mathrm{H}_{2}$ has good storage opportunities with very few losses even over long time horizons. The reconversion of $\mathrm{H}_{2}$ to power via fuel cells is, however, limited by lower efficiencies (than other ESS) and very specific temperature requirements [189]. If a gas turbine is used for reconverting $\mathrm{H}_{2}$, traditional modeling approaches may be used. EV have additional degrees of freedom. They can be connected or disconnected and may change location [60]. The literature provides exhaustive reviews of ESS qualities in power systems [24,25,30,190-193]. Two recently published books [47,194] in German may provide further insights on these topics.

Modeling the abovementioned technical characteristics within SEP can increase the solving times significantly and lead to a loss of linearity. The time-dependent constraints (starting times, energy balances, ramps) are especially challenging, as they require a sequential time treatment as well as a high temporal resolution. However, not modeling them accordingly may imply attaining suboptimal results in SEP.

\subsection{ESS' complex lifetime and efficiency functions need to be modeled}

The many ESS exhibit large differences, not only between each other but also within a single technology, being characterized by complex efficiency and lifetime functions. The lifetime and efficiency of both generators and ESS are affected by cycling [7], consequently impacting their (re-) investment and maintenance costs. However, ESS are exposed to a larger number of cycles. For example, batteries could perform multiple cycles per day.

Lifetime as a function of cycling has been considered in expansion decisions of conventional generators [195], as well as in operation of small power systems [196]. In SEP, however, we detected that only one study has looked into cycling so far [89]. This implies that the optimal results found by the remaining studies may hide infeasible conditions. For example, nothing in the model would prevent a BESS performing cycles beyond its lifetime expectations.

The efficiency of ESS is more dynamic than that of conventional power plants. It is sensitive to the state of charge, state of health, charging and discharging power flows, and operating temperatures, among others [25]. These complex dependencies provoke large deviations in their operating efficiency as compared to generators and hence lead to greater uncertainties. SEP blind 
to this phenomenon may over- or under-estimate the actual efficiencies, as well as be indifferent to lower states-of-charge and the involved smaller efficiencies. If these relationships are implemented, the optimization problem frequently becomes nonlinear.

\subsection{ESS require high temporal and spatial resolution}

In modeling, coarse time scales may mask relevant short-term dynamics. This happens in GEP with vRES, but also in SEP. Furthermore, the technical differences among ESS (Section 4.1) can only be distinguished, if a matching temporal and spatial resolution is used. Moreover, important technical aspects of ESS, including ramping rates, variable efficiency, and reserve services, require sequential approaches. Although our review has shown that time resolution has improved significantly over the years, and is down to hourly resolutions, solving the entire planning horizon (e.g. 20 years) with that resolution is still not feasible in real power systems.

The chronology is frequently given up in trade of cross-sectorial planning, such as in the wide-spread expansion software MARKAL [95] and TIMES [197]. Here, vRES are mainly represented with capacity credits, which neglect their variable input. In power systems with high shares of vRES, ignoring their spatial and temporal variability leads to systematic errors, especially what refers to the need for ramp rates, forecast process and the quantification of operating reserves. As a consequence, simplified planning approaches may underestimate the real need of flexibility in the system $[13,198,199]$. In more recent versions of those programs, typical days or typical weeks are included as a possible solution to overcome these shortcomings [200]. Short-term storage systems can then be modeled with the time resolution they require. Nevertheless, type-days (or weeks) have two strong limitations: i) it becomes increasingly more difficult to identify them in the presence of many stochastic drivers (vRES) in the system; ii) the approach cannot deal with large storage capacities that exceed the length of the typical time period.

A potential solution for these issues is the use of hybrid models (for the definition see Section 0). As mentioned in Section 3.9, some hybrid SEP propose to optimize the operation and find the best ESS size by scenario inspection [84,172]. This nonetheless, depends strongly on the good luck of the planning expert and is hardly scalable to SEP with multi ESS, due to the numerous scenarios it would require. But, it may still provide a good initial solution for storage requirements. The other hybrids (which feed the operational costs back to the investment optimization [121]) are plagued by convergence issues and depend on configuring a good set of rules to describe the operation. Some researchers [129] propose to hard-link separated investment and operation programs. This means performing a long-term expansion planning (e.g. TIMES) followed by an operational model that feeds back constraints. So far they have been able to study the Portuguese power system. But, whether the framework holds for multi-storage, multi-sector, and nonlinearities, is unclear.

Similarly to vRES, many ESS rely on local resources, such as PHS in the mountains, CAES in special rock formations or EV in wealthy neighborhoods. Consequently, studying the local potentials becomes more relevant. Another corollary is that the transmission system and its expansion need to be modeled with more detail. But, this increases the computational burden.

In short, to capture the variable nature of vRES and the short-term dynamics of ESS, the temporal resolutions has to be further improved. Similarly, to address local potentials and bottlenecks, the spatial resolution needs to be enhanced.

\subsection{ESS' multiple services need to be recognized}

ESS can provide multiple services, from energy shifting and ramping capabilities to cope with vRES variability, reserves to compensate forecasting errors of vRES (uncertainty), improved frequency and voltage control, stability support, and black-start capability, among others. These applications are well documented $[3,25,30,191]$ and some publications demonstrate that it is critical to properly consider what services ESS should provide from an operational point of view [201]. However, only few SEP publications include the pertinent benefits. Consequently, the value of ESS is systematically being underestimated.

More worryingly, current reserves, given primarily by conventional generators, are decreasing and being replaced by inertialess converters (PV and wind power) [3]. In high vRES-shares scenarios, ESS might be the main source of reserves to deal with increasing levels of variability and uncertainties.

In the context of multi-sectorial planning (Section 4.5), more system services might emerge in time, which could be provided by ESS. For example, hydropower plants usually provide flexibility for vRES integration, but this operation (hydropeaking) [202204] has detrimental effects on the ecosystems of rivers, such as washing out and stranding of species [205], life cycle and food chain disruption [206]. Hence, if other ESS provide that flexibility, they could indirectly provide an ecosystemic service by reducing the hydropeaking.

In order to give the right price signals for investment decisions, the many services that ESS are able to provide in the power system, as well as across energy sectors, must be acknowledged. For this, the above-mentioned challenges need to be addressed.

\subsection{ESS' presence in many energy sectors require multi-sectoral approaches to be extended}

Within the electricity sector, investment decisions of the different flexibility sources are interdependent [39]. However, they are frequently planned separately. A holistic approach, instead, would enable identifying synergies. For example, a combined storage and transmission expansion planning allows for a more economic integration of vRES [101,121]. In other words, if the transmission is cheap, remote generation and ESS potentials can easily be accessed. Conversely, local generation and ESS resources would be preferred. Here, the value of ESS lies in decreasing transmission congestion and losses, as well as displacing its socially controversial expansion [39].

Nowadays, the economic potential of ESS transcends the electricity sector; also the heat, gas, water and transport sector offer attractive ESS options. Reasons to include multi-sectors in SEP are at least the following: i) some cross-sectorial potential of ESS is convenient as it already exists or can be implemented through minor adaptions; for example, electric boilers for hot water and heat pumps for space heating may be a key low-cost option for providing flexibility [65,66]; similarly, $\mathrm{H}_{2}$ attained from P2G can be stored and transmitted in existing gas infrastructure to some extent [69,72]; and ii) cross-sectorial SEP allows identifying 
synergies between sectors: for example, more gas storage can increase the sector's autonomy and simultaneously reduce the need for other long-term storage options, such as large reservoirs that often are controversial; or a desalination plant could perceive another stream of income when offering operational flexibility to the power sector [155]; iii) cross-sectorial SEP helps identifying the possible issues that could arise when the coupling is not explicitly modeled: a recent work [69] (model of the integrated electricity and gas network flexibility, facilitated by the storage available in the gas lines) highlights how the lack of storage flexibility in the gas network might cause issues with reserve commitment and delivery in the electrical sector. Moreover, as electrification of energy demand is envisioned by the International Energy Agency as a major solution for meeting $\mathrm{CO}_{2}$ reduction goals [207], the electricity sector is no longer isolated and is growing closer together with the heat, gas, water and transport sectors.

Modeling more than just the power sector imposes computational burdens, just as the spatial and time resolution does. An open question is where the value of ESS lies. Is it in the multiple services that a mix of ESS can provide in the electricity sector, or is it the energy shifting ability across sectors and time?

\section{Conclusions and future work}

This paper reviewed about 90 journal publications involving storage expansion planning (SEP). It classified them according to nine criteria, including modeled energy storage systems (ESS), goal and planning perspective of models, energy sectors and flexibility options, network modeling, modeling detail of ESS and power system, time treatment of investment decisions, time treatment of system operation, treatment of uncertainty, and solution methods. From this classification, trends in SEP were identified and the outstanding challenges derived. These challenges are summarized as follows.

\subsection{ESS' diversity needs to be addressed}

Nowadays, SEP focuses on a wide spectrum of ESS, including short- to long-term, fixed and mobile, centralized and distributed ESS, all very dissimilar to each other. As the ideal ESS does not exist, the search for an optimum combination or mix of technologies seems natural. However, only now the first studies to identify that optimal ESS mix are appearing. So far, these studies limit the modeling details of ESS to a handful of parameters (state of charge, roundtrip efficiency, power, and energy capacity), neglecting other relevant dynamics.

\subsection{ESS' complex lifetime and efficiency functions need to be modeled}

In contrast to conventional technologies in generation expansion planning (GEP), the lifetime of ESS is strongly affected by the many cycles to which they are exposed, and their efficiency depends on diverse phenomena making the model highly nonlinear. Modeling the lifetime in terms of cycling, as well as the efficiency functions of ESS remain scarce in SEP, but is required for not underestimating the costs.

\subsection{ESS require high temporal and spatial resolution}

The above mentioned technical diversity of ESS calls for a higher temporal resolution, whereas transmission constraints and local potentials of ESS call for a more detailed spatial resolution. Only a sufficient treatment of space and time and modeling their multiple services (see next point), as well as a complete modeling of the power system operation (e.g. unit commitment and network constraints), will enable capturing the full value of ESS.

\subsection{ESS' multiple services need to be recognized}

To integrate variable renewable energy systems (vRES), flexibility of energy systems in terms of energy shifting, ramps and regulation is needed. These are all qualities of ESS. However, current SEP focuses mainly on energy shifting, systemically underestimating their full value. This is relevant especially as ESS is a potential competitor to other flexibility sources, such as transmission and generation infrastructure, and demand-side management. Furthermore, only a joint planning of them allows identifying the global optimum of flexibility in future energy systems.

\subsection{ESS' presence in many energy sectors require multi-sectoral approaches to be extended}

ESS can be deployed in many energy sectors. Moreover, ESS may readily be available in other energy sectors, so that relatively low-cost options for power system flexibility provision may be accessed. Furthermore, the sectors are growing together as electrification of demand is widely envisioned as a solution for reaching climate change mitigation goals. Consequently, to find the cross-sectorial optima, the power, heat, gas, transport and water sectors need to be planned in conjunction.

\subsection{Future work}

As future work, the aforementioned SEP challenges need to be addressed. In particular, elaborating a comprehensive ranking between them is pressing. For example, a benchmark for the trade-off between precision and computing time among the many technical ESS properties, time and space resolution, and detail of the power system is needed. Furthermore, towards multi-sectorial storage planning, a coordinated planning effort among the involved energy sectors is key.

Future SEP approaches might also emphasize agent-based modeling, stochastic programming, and multi-objective optimization, in order to capture market behavior, uncertainties, and multiple targets, such as environmental criteria, flexible planning, and resilience, of the energy sector.

Finally, the combination of a high resolution of time, space, technical phenomena, and market, along with multi-sectors -and all these under uncertainty- calls for advances in model reduction techniques and solving speed. 


\section{Acknowledgements}

The authors thank the support of the DAAD, the Chilean Council of Scientific and Technological Research (CONICYT/ FONDAP/15110019, CONICYT/ FONDECYT/1151438) and EPSRC through the HubNet project (EP/I013636/1). Helpful remarks from Frank Leañez about time structure and assistance from Jonas Schradi in Fig. 4 are also appreciated. 


\section{References}

[1] REN21. Renewables 2015 Global Status Report. Paris: 2015.

[2] Holttinen H. Hourly wind power variations in the Nordic countries. Wind Energy 2005;8:173-95. doi:10.1002/we.144.

[3] Carvalho PMS, Ferreira L a FM, Krogh BH, Popli N, Ilić MD. Wind Integration in Power Systems: Operational Challenges and Possible Solutions. Proc IEEE 2011;99:214-32. doi:10.1109/JPROC.2010.2070051.

[4] North American Electric Reliability Corporation. Accommodating High Levels of Variable Generation. Princeton, NJ: 2009.

[5] Cochran J, Miller M, Zinaman O, Milligan M, Arent D, Palmintier B, et al. Flexibility in 21st Century Power Systems 2014. doi:10.2172/1130630.

[6] Lannoye E, Flynn D, O’Malley M. The role of power system flexibility in generation planning. Power Energy Soc. Gen. Meet., IEEE; 2011, p. 1-6. doi:10.1109/PES.2011.6039009.

[7] Lew D, Brinkman G, Kumar N, Lefton S, Jordan G, Venkataraman S. Finding Flexibility: Cycling the Conventional Fleet. IEEE Power Energy Mag 2013;11:20-32. doi:10.1109/MPE.2013.2277988.

[8] Bouffard F, Galiana FD. Stochastic security for operations planning with significant wind power generation. IEEE Trans Power Syst 2008;23:306-16. doi:10.1109/TPWRS.2008.919318.

[9] Tuohy A, Meibom P, Denny E, O’Malley M. Unit Commitment for Systems with Significant Wind Penetration. Power 2009;24:592-601. doi:10.1109/TPWRS.2009.2016470.

[10] Pereira-Bonvallet E, Suazo-Martinez C, Palma-Behnke R. A stochastic unit commitment policy for wind power uncertainty integrating corrective actions. 2013 IEEE Power Energy Soc. Gen. Meet., IEEE; 2013, p. 1-5. doi:10.1109/PESMG.2013.6672994.

[11] Venne P, Guillaud X, Teodorescu R, Mahseredjian J. Generalized Gain Scheduling for Deloaded Wind Turbine Operation. Wind Eng 2010;34:219-40. doi:10.1260/0309-524X.34.2.219.

[12] Rahmann C, Vittal V, Ascui J, Haas J. Mitigation Control Against Partial Shading Effects in Large-Scale PV Power Plants. IEEE Trans Sustain Energy 2016;7:173-80. doi:10.1109/TSTE.2015.2484261.

[13] Deane JP, Drayton G, Ó Gallachóir BP. The impact of sub-hourly modelling in power systems with significant levels of renewable generation. Appl Energy 2014;113:152-8. doi:10.1016/j.apenergy.2013.07.027.

[14] De Jonghe C, Hobbs BF, Belmans R. Integrating short-term demand response into long-term investment planning. 2011.

[15] Østergaard PA. Ancillary services and the integration of substantial quantities of wind power. Appl Energy 2006;83:451-63. doi:10.1016/j.apenergy.2005.04.007.

[16] Böttger D, Götz M, Lehr N, Kondziella H, Bruckner T. Potential of the Power-to-Heat Technology in District Heating Grids in Germany. Energy Procedia 2014;46:246-53. doi:10.1016/j.egypro.2014.01.179.

[17] Østergaard PA. Comparing electricity, heat and biogas storages' impacts on renewable energy integration. Energy 2012;37:255-62. doi:10.1016/j.energy.2011.11.039.

[18] Mancarella P. MES (multi-energy systems): An overview of concepts and evaluation models. Energy 2014;65:1-17. doi:10.1016/j.energy.2013.10.041.

[19] Auer H, Obersteiner C, Weissensteiner L, Resch G. Guiding a Least Cost Grid Integration of RES- Electricity in an Extended Europe: System Operation Cost and Grid Reinforcement/Extension Cost Allocated to Large-Scale RES-E Integration. Vienna: 2005.

[20] Swider DJ, et mult. Guiding a least cost grid integration of RES- electricity in an extended Europe: Case Studies on conditions and costs for RES-E grid integration. 2006. doi:S07.38561.

[21] Huber M, Dimkova D, Hamacher T. Integration of wind and solar power in Europe: Assessment of flexibility requirements. Energy 2014;69:236-46. doi:10.1016/j.energy.2014.02.109.

[22] Bertsch J, Growitsch C, Lorenczik S, Nagl S. Flexibility in Europe's power sector - An additional requirement or an automatic complement? Energy Econ 2014. doi:10.1016/j.eneco.2014.10.022.

[23] Rahman F, Rehman S, Abdul-Majeed MA. Overview of energy storage systems for storing electricity from renewable energy sources in Saudi Arabia. Renew Sustain Energy Rev 2012;16:274-83. doi:10.1016/j.rser.2011.07.153.

[24] Zhao H, Wu Q, Hu S, Xu H, Rasmussen CN. Review of energy storage system for wind power integration support. Appl Energy 2014;137:545-53. doi:10.1016/j.apenergy.2014.04.103.

[25] Beaudin M, Zareipour H, Schellenberglabe A, Rosehart W. Energy storage for mitigating the variability of renewable electricity sources: An updated review. Energy Sustain Dev 2010;14:302-14. doi:10.1016/j.esd.2010.09.007.

[26] Suazo-Martinez C, Pereira-Bonvallet E, Palma-Behnke R, Zhang X-P. Impacts of Energy Storage on Short Term Operation Planning Under Centralized Spot Markets. IEEE Trans Smart Grid 2014;5:1110-8. doi:10.1109/TSG.2013.2281828.

[27] Denholm P, Hand M. Grid flexibility and storage required to achieve very high penetration of variable renewable electricity. Energy Policy 2011;39:1817-30. doi:10.1016/j.enpol.2011.01.019.

[28] Ibrahim H, Ilinca a, Perron J. Energy storage systems-Characteristics and comparisons. Renew Sustain Energy Rev 2008;12:1221-50. doi:10.1016/j.rser.2007.01.023.

[29] Hall PJ, Bain EJ. Energy-storage technologies and electricity generation. Energy Policy 2008;36:4352-5. doi:10.1016/j.enpol.2008.09.037.

[30] Yekini Suberu M, Wazir Mustafa M, Bashir N. Energy storage systems for renewable energy power sector integration and mitigation of intermittency. Renew Sustain Energy Rev 2014;35:499-514. doi:10.1016/j.rser.2014.04.009.

[31] Luss H. Operations Research and Capacity Expansion Problems: A Survey. Oper Res 1982;30:907-47. doi:10.1287/opre.30.5.907.

[32] Farghal SA, Abdel Aziz MR. Generation expansion planning including the renewable energy sources. IEEE Trans Power Syst 1988;3:816-22. doi:10.1109/59.14527.

[33] Sanghvi AP. Least-cost energy strategies for power system expansion. Energy Policy 1984;12:75-92. doi:10.1016/0301-4215(84)90089-2.

[34] Koomey J, Rosenfeld AH, Gadgil A. Conservation screening curves to compare efficiency investments to power plants. Energy Policy 1990;18:77482. doi:10.1016/0301-4215(90)90030-8.

[35] Dehghan S, Amjady N, Kazemi A. Two-Stage Robust Generation Expansion Planning: A Mixed Integer Linear Programming Model. IEEE Trans Power Syst 2014;29:584-97. doi:10.1109/TPWRS.2013.2287457.

[36] Fang R, Hill DJ. A New Strategy for Transmission Expansion in Competitive Electricity Markets. IEEE Power Eng Rev 2002;22:60-60. doi:10.1109/MPER.2002.4311839.

[37] Latorre G, Cruz RD, Areiza JM, Villegas A. Classification of publications and models on transmission expansion planning. IEEE Trans Power Syst 2003;18:938-46. doi:10.1109/TPWRS.2003.811168.

[38] Aghaei J, Amjady N, Baharvandi A, Akbari M. Generation and Transmission Expansion Planning: MILP-Based Probabilistic Model. IEEE Trans Power Syst 2014;29:1592-601. doi:10.1109/TPWRS.2013.2296352.

[39] Hedayati M, Zhang J, Hedman KW. Joint transmission expansion planning and energy storage placement in smart grid towards efficient integration of renewable energy. 2014 IEEE PES T\&D Conf. Expo., IEEE; 2014, p. 1-5. doi:10.1109/TDC.2014.6863213.

[40] Hemmati R, Hooshmand R-A, Khodabakhshian A. Comprehensive review of generation and transmission expansion planning. IET Gener Transm Distrib 2013;7:955-64. doi:10.1049/iet-gtd.2013.0031.

[41] Hobbs BF. Optimization methods for electric utility resource planning. Eur J Oper Res 1995;83:1-20. doi:10.1016/0377-2217(94)00190-N.

[42] Hemmati R, Hooshmand R-A, Khodabakhshian A. State-of-the-art of transmission expansion planning: Comprehensive review. Renew Sustain Energy 
Rev 2013;23:312-9. doi:10.1016/j.rser.2013.03.015.

[43] Quintero J, Zhang H, Chakhchoukh Y, Vittal V, Heydt GT. Next Generation Transmission Expansion Planning Framework: Models, Tools, and Educational Opportunities. IEEE Trans Power Syst 2014;29:1911-8. doi:10.1109/TPWRS.2014.2317590.

[44] Barati F, Seifi H, Nateghi A, Sepasian MS, Shafie-khah M, Catalao JPS. An integrated generation, transmission and Natural Gas Grid Expansion Planning approach for large scale systems. 2015 IEEE Power Energy Soc. Gen. Meet., IEEE; 2015, p. 1-5. doi:10.1109/PESGM.2015.7286535.

[45] Connolly D, Lund H, Mathiesen BV, Leahy M. A review of computer tools for analysing the integration of renewable energy into various energy systems. Appl Energy 2010;87:1059-82. doi:10.1016/j.apenergy.2009.09.026.

[46] Foley A, Ó Gallachóir BP, Hur J, Baldick R, McKeogh EJ. A strategic review of electricity systems models. Energy 2010;35:4522-30. doi:10.1016/j.energy.2010.03.057.

[47] Sterner M, Stadler I. Energiespeicher - Bedarf, Technologien, Integration. Berlin, Heidelberg: Springer Berlin Heidelberg; 2014. doi:10.1007/978-3642-37380-0.

[48] Kirschen D, Strbac G. Fundamentals of Power System Economics. Chichester, UK: John Wiley \& Sons, Ltd; 2004. doi:10.1002/0470020598.

[49] Han X, Ji T, Zhao Z, Zhang H. Economic evaluation of batteries planning in energy storage power stations for load shifting. Renew Energy 2015;78:6437. doi:10.1016/j.renene.2015.01.056.

[50] Zhou Y, Wang L, McCalley JD. Designing effective and efficient incentive policies for renewable energy in generation expansion planning. Appl Energy 2011;88:2201-9. doi:10.1016/j.apenergy.2010.12.022.

[51] Bloom J, Charny L. Long Range Generation Planning With Limited Energy and Storage Plants Part I: Production Costing. IEEE Trans Power Appar Syst 1983;PAS-102:2861-70. doi:10.1109/TPAS.1983.318167.

[52] Toyoda J, Kohno M. Coordinative planning of energy storage system in optimal generation mix. Electr Eng Japan 1986;106:279-85. doi:10.1002/eej.4391060312.

[53] Yasuda K, Nishiya K, Hasegawa J, Yokoyama R. Optimal Generation Expansion Planning with Electric Energy Storage Systems. 14th Annu. Conf. Ind. Electron. Soc., vol. 3, IEEE; 1988, p. 550-5. doi:10.1109/IECON.1988.665742.

[54] Youn LTO, Lee KY, Park YM. Optimal Long-Range Generation Expansion Planning for Hydro-Thermal System Based on Analytical Production Costing Model. IEEE Trans Power Syst 1987;2:278-84. doi:10.1109/TPWRS.1987.4335119.

[55] Kandil MS, Farghal S a., Hasanin NE. Economic assessment of energy storage options in generation expansion planning. IEE Proc C Gener Transm Distrib 1990;137:298. doi:10.1049/ip-c.1990.0040.

[56] Alarcon-Rodriguez A, Ault G, Galloway S. Multi-objective planning of distributed energy resources: A review of the state-of-the-art. Renew Sustain Energy Rev 2010;14:1353-66. doi:10.1016/j.rser.2010.01.006.

[57] Das T, Krishnan V, McCalley JD. Assessing the benefits and economics of bulk energy storage technologies in the power grid. Appl Energy 2015;139:104-18. doi:10.1016/j.apenergy.2014.11.017.

[58] Qi W, Liang Y, Shen Z-JM. Joint Planning of Energy Storage and Transmission for Wind Energy Generation. Oper Res 2015;63:1280-93. doi:10.1287/opre.2015.1444.

[59] Deb K, Deb K. Multi-objective Optimization. Search Methodol., Boston, MA: Springer US; 2014, p. 403-49. doi:10.1007/978-1-4614-6940-7_15.

[60] Mena R, Hennebel M, Li Y-F, Ruiz C, Zio E. A risk-based simulation and multi-objective optimization framework for the integration of distributed renewable generation and storage. Renew Sustain Energy Rev 2014;37:778-93. doi:10.1016/j.rser.2014.05.046.

[61] Chicco G, Mancarella P. From Cogeneration to Trigeneration: Profitable Alternatives in a Competitive Market. IEEE Trans Energy Convers 2006;21:265-72. doi:10.1109/TEC.2005.858089.

[62] Chicco G, Mancarella P. Distributed multi-generation systems: energy models and analyses. New York, NY: Nova Science Publishers; 2009.

[63] Chicco G, Mancarella P. Distributed multi-generation: A comprehensive view. Renew Sustain Energy Rev 2009;13:535-51. doi:10.1016/j.rser.2007.11.014.

[64] Ummels BC, Pelgrum E, Kling WL. Integration of large-scale wind power and use of energy storage in the Netherlands' electricity supply. IET Renew Power Gener 2008;2:34-46. doi:10.1049/iet-rpg:20070056.

[65] Capuder T, Mancarella P. Techno-economic and environmental modelling and optimization of flexible distributed multi-generation options. Energy 2014;71:516-33. doi:10.1016/j.energy.2014.04.097.

[66] Mancarella P, Chicco G. Real-Time Demand Response From Energy Shifting in Distributed Multi-Generation. IEEE Trans Smart Grid 2013;4:192838. doi:10.1109/TSG.2013.2258413.

[67] Mathiesen BV, Lund H. Comparative analyses of seven technologies to facilitate the integration of fluctuating renewable energy sources. IET Renew Power Gener 2009;3:190. doi:10.1049/iet-rpg:20080049.

[68] Lund H, Kempton W. Integration of renewable energy into the transport and electricity sectors through V2G. Energy Policy 2008;36:3578-87. doi:10.1016/j.enpol.2008.06.007.

[69] Clegg S, Mancarella P. Integrated Electrical and Gas Network Flexibility Assessment in Low-Carbon Multi-Energy Systems. IEEE Trans Sustain Energy 2016;7:718-31. doi:10.1109/TSTE.2015.2497329.

[70] Shahidehpour M, Yong Fu, Wiedman T. Impact of Natural Gas Infrastructure on Electric Power Systems. Proc IEEE 2005;93:1042-56. doi:10.1109/JPROC.2005.847253.

[71] de Boer HS, Grond L, Moll H, Benders R. The application of power-to-gas, pumped hydro storage and compressed air energy storage in an electricity system at different wind power penetration levels. Energy 2014;72:360-70. doi:10.1016/j.energy.2014.05.047.

[72] Clegg S, Mancarella P. Storing renewables in the gas network: modelling of power-to-gas seasonal storage flexibility in low-carbon power systems. IET Gener Transm Distrib 2016;10:566-75. doi:10.1049/iet-gtd.2015.0439.

[73] Arthington AH, Naiman RJ, McClain ME, Nilsson C. Preserving the biodiversity and ecological services of rivers: New challenges and research opportunities. Freshw Biol 2010;55:1-16. doi:10.1111/j.1365-2427.2009.02340.x.

[74] Pérez-Díaz JI, Millán R, García D, Guisández I, Wilhelmi JR. Contribution of re-regulation reservoirs considering pumping capability to environmentally friendly hydropower operation. Energy 2012;48:144-52. doi:10.1016/j.energy.2012.06.071.

[75] Novosel T, Ćosić B, Krajačić G, Duić N, Pukšec T, Mohsen MS, et al. The influence of reverse osmosis desalination in a combination with pump storage on the penetration of wind and PV energy: A case study for Jordan. Energy 2014;76:73-81. doi:10.1016/j.energy.2014.03.088.

[76] Rasmussen MG, Andresen GB, Greiner M. Storage and balancing synergies in a fully or highly renewable pan-European power system. Energy Policy 2012;51:642-51. doi:10.1016/j.enpol.2012.09.009.

[77] Loisel R, Mercier A, Gatzen C, Elms N, Petric H. Valuation framework for large scale electricity storage in a case with wind curtailment. Energy Policy 2010;38:7323-37. doi:10.1016/j.enpol.2010.08.007.

[78] Martinez Cesena EA, Capuder T, Mancarella P. Flexible Distributed Multienergy Generation System Expansion Planning Under Uncertainty. IEEE Trans Smart Grid 2016;7:348-57. doi:10.1109/TSG.2015.2411392.

[79] Stott B, Jardim J, Alsac O. DC Power Flow Revisited. IEEE Trans Power Syst 2009;24:1290-300. doi:10.1109/TPWRS.2009.2021235.

[80] dos Santos TN, Diniz AL. A Dynamic Piecewise Linear Model for DC Transmission Losses in Optimal Scheduling Problems. IEEE Trans Power Syst 2011;26:508-19. doi:10.1109/TPWRS.2010.2057263.

[81] Overbye TJ, Xu Cheng, Yan Sun. A comparison of the AC and DC power flow models for LMP calculations. 37th Annu. Hawaii Int. Conf. Syst. Sci., IEEE; 2004, p. 9. doi:10.1109/HICSS.2004.1265164. 
[82] Rider MJ, Garcia AV, Romero R. Power system transmission network expansion planning using AC model. IET Gener Transm Distrib 2007;1:731. doi:10.1049/iet-gtd:20060465.

[83] Kaldellis JK, Zafirakis D. Optimum energy storage techniques for the improvement of renewable energy sources-based electricity generation economic efficiency. Energy 2007;32:2295-305. doi:10.1016/j.energy.2007.07.009.

[84] Suazo-Martínez C, Pereira-Bonvallet E, Palma-Behnke R. A Simulation Framework for Optimal Energy Storage Sizing. Energies 2014;7:3033-55. doi:10.3390/en7053033.

[85] Steffen B, Weber C. Efficient storage capacity in power systems with thermal and renewable generation. Energy Econ 2013;36:556-67. doi:10.1016/j.eneco.2012.11.007.

[86] Sanghvi AP, Shavel IH. Investment Planning for Hydro-Thermal Power System Expansion: Stochastic Programming Employing the Dantzig-Wolfe Decomposition Principle. IEEE Trans Power Syst 1986;1:115-21. doi:10.1109/TPWRS.1986.4334916.

[87] Arabali A, Ghofrani M, Etezadi-Amoli M, Fadali MS. Stochastic Performance Assessment and Sizing for a Hybrid Power System of Solar/Wind/Energy Storage. IEEE Trans Sustain Energy 2014;5:363-71. doi:10.1109/TSTE.2013.2288083.

[88] Rajesh K, Karthikeyan K, Kannan S, Thangaraj C. Generation expansion planning based on solar plants with storage. Renew Sustain Energy Rev 2016;57:953-64. doi:10.1016/j.rser.2015.12.126.

[89] Hajipour E, Bozorg M, Fotuhi-Firuzabad M. Stochastic Capacity Expansion Planning of Remote Microgrids With Wind Farms and Energy Storage. IEEE Trans Sustain Energy 2015;6:491-8. doi:10.1109/TSTE.2014.2376356.

[90] Dvijotham K, Backhaus S, Chertkov M. Operations-Based Planning for Placement and Sizing of Energy Storage in a Grid With a High Penetration of Renewables 2011;98195.

[91] Fares RL, Meyers JP. Economic Operational Planning of Grid-connected Battery Energy Storage. ECS Trans 2013;45:1-16. doi:10.1149/04526.0001ecst.

[92] Crossland AF, Jones D, Wade NS. Planning the location and rating of distributed energy storage in LV networks using a genetic algorithm with simulated annealing. Int J Electr Power Energy Syst 2014;59:103-10. doi:10.1016/j.ijepes.2014.02.001.

[93] Barton JP, Infield DG. Energy storage and its use with intermittent renewable energy. IEEE Trans Energy Convers 2004;19:441-8. doi:10.1109/TEC.2003.822305.

[94] Heaps CG. Long-range Energy Alternatives Planning (LEAP) system 2012.

[95] International Energy Agency. MARKAL 2014.

[96] Argonne National Laboratory. Energy and Power Evaluation Program (ENPEP-BALANCE) 2009.

[97] U.S. Energy Information Administration Data. National Energy Modelling System (NEMS) 1993.

[98] HOMER Energy. HOMER Pro 2015.

[99] Sustainable Energy Planning Research group at Aalborg University. EnergyPLAN 2015.

[100] Energy Exemplar. PLEXOS Integrated Energy Model 2015.

[101] Haller M, Ludig S, Bauer N. Decarbonization scenarios for the EU and MENA power system: Considering spatial distribution and short term dynamics of renewable generation. Energy Policy 2012;47:282-90. doi:10.1016/j.enpol.2012.04.069.

[102] Rudnick H, Palma R, Cura E, Silva C. Economically adapted transmission systems in open access schemes-application of genetic algorithms. Power Syst IEEE Trans 1996;11:1427-40.

[103] Haller M, Ludig S, Bauer N. Bridging the scales: A conceptual model for coordinated expansion of renewable power generation, transmission and storage. Renew Sustain Energy Rev 2012;16:2687-95. doi:10.1016/j.rser.2012.01.080.

[104] Sun N. Modellgestützte Untersuchung des Elektrizitätsmarktes -Kraftwerkseinsatzplanung und -investitionen (Model based analysis of the electricity market - unit commitment and investments). University of Stuttgart, 2013.

[105] Palma-Behnke R, Benavides C, Lanas F, Severino B, Reyes L, Llanos J, et al. A Microgrid Energy Management System Based on the Rolling Horizon Strategy. IEEE Trans Smart Grid 2013;4:996-1006. doi:10.1109/TSG.2012.2231440.

[106] McAllister CD, Ryan SM. Relative risk characteristics of rolling horizon hedging heuristics for capacity expansion. Eng Econ 2000;45:115-28. doi:10.1080/00137910008967540.

[107] Rahmann C, Palma-Behnke R. Optimal Allocation of Wind Turbines by Considering Transmission Security Constraints and Power System Stability. Energies 2013;6:294-311. doi:10.3390/en6010294.

[108] Brown P, Peas Lopes JA, Matos MA. Optimization of Pumped Storage Capacity in an Isolated Power System With Large Renewable Penetration. IEEE Trans Power Syst 2008;23:523-31. doi:10.1109/TPWRS.2008.919419.

[109] Xing H, Cheng H, Zhang Y, Zeng P. Active distribution network expansion planning integrating dispersed energy storage systems. IET Gener Transm Distrib 2016;10:638-44. doi:10.1049/iet-gtd.2015.0411.

[110] Laux H, Gillenkirch RM, Schenk-Mathes HY. Entscheidungstheorie. Berlin, Heidelberg: Springer Berlin Heidelberg; 2014. doi:10.1007/978-3-64255258-8.

[111] Gorenstin BG, Campodonico NM, Costa JP, Pereira MVF. Power system expansion planning under uncertainty. IEEE Trans Power Syst 1993;8:12936. doi:10.1109/59.221258.

[112] Wallace SW, Fleten S-E. Stochastic Programming Models in Energy. Handbooks Oper. Res. Manag. Sci., vol. 10, Elsevier; 2003 , p. $637-77$. doi:10.1016/S0927-0507(03)10010-2.

[113] Sagastizábal C. Divide to conquer: decomposition methods for energy optimization. Math Program 2012;134:187-222. doi:10.1007/s10107-012-05707.

[114] Kitapbayev Y, Moriarty J, Mancarella P. Stochastic control and real options valuation of thermal storage-enabled demand response from flexible district energy systems. Appl Energy 2015;137:823-31. doi:10.1016/j.apenergy.2014.07.019.

[115] Meibom P, Barth R, Hasche B, Brand H, Weber C, O’Malley M. Stochastic Optimization Model to Study the Operational Impacts of High Wind Penetrations in Ireland. IEEE Trans Power Syst 2011;26:1367-79. doi:10.1109/TPWRS.2010.2070848.

[116] Bradley S, Hax A, Magnanti T. Applied mathematical programming 1977.

[117] El Metwally MM, Harb AM. Transmission planning using admittance approach and quadratic programming. Electr Mach Power Syst 1993;21:69-83. doi:10.1080/07313569308909635.

[118] Sullivan R. Power system planning. New York: McGraw-Hill; 1977.

[119] Pereira MVF, Pinto LMVG. Multi-stage stochastic optimization applied to energy planning. Math Program 1991;52:359-75. doi:10.1007/BF01582895.

[120] Brekken TK a, Yokochi A, von Jouanne A, Yen ZZ, Hapke HM, Halamay D a. Optimal Energy Storage Sizing and Control for Wind Power Applications. IEEE Trans Sustain Energy 2011;2:69-77. doi:10.1109/TSTE.2010.2066294.

[121] Bussar C, Moos M, Alvarez R, Wolf P, Thien T, Chen H, et al. Optimal Allocation and Capacity of Energy Storage Systems in a Future European Power System with 100\% Renewable Energy Generation. Energy Procedia 2014;46:40-7. doi:10.1016/j.egypro.2014.01.156.

[122] Saboori H, Hemmati R, Abbasi V. Multistage distribution network expansion planning considering the emerging energy storage systems. Energy Convers Manag 2015;105:938-45. doi:10.1016/j.enconman.2015.08.055.

[123] Viveka R, Kalyani S, Devie PM. Optimal Planning of Energy Storage Systems in Transmission Networks using Evolutionary Algorithm. Int J Emerg Eng Res Technol 2015;3:83-97.

[124] Kannan S, Slochanal SMR, Padhy NP. Application and Comparison of Metaheuristic Techniques to Generation Expansion Planning Problem. IEEE 
Trans Power Syst 2005;20:466-75. doi:10.1109/TPWRS.2004.840451.

[125] Lee KY, El-Sharkawi MA. Modern Heuristic Optimization Techniques: Theory and Applications to Power Systems. John Wiley \& Sons; 2008.

[126] Schoenung SM, Burns C. Utility energy storage applications studies. IEEE Trans Energy Convers 1996;11:658-65. doi:10.1109/60.537039.

[127] Sundararagavan S, Baker E. Evaluating energy storage technologies for wind power integration. Sol Energy 2012;86:2707-17. doi:10.1016/j.solener.2012.06.013.

[128] Makarov Y V., Du P, Kintner-Meyer MCW, Jin C, Illian HF. Sizing Energy Storage to Accommodate High Penetration of Variable Energy Resources. IEEE Trans Sustain Energy 2012;3:34-40. doi:10.1109/TSTE.2011.2164101.

[129] Pina A, Silva CA, Ferrão P. High-resolution modeling framework for planning electricity systems with high penetration of renewables. Appl Energy 2013;112:215-23. doi:10.1016/j.apenergy.2013.05.074.

[130] Rosen J, Tietze-Stöckinger I, Rentz O. Model-based analysis of effects from large-scale wind power production. Energy 2007;32:575-83. doi:10.1016/j.energy.2006.06.022.

[131] Baños R, Manzano-Agugliaro F, Montoya FG, Gil C, Alcayde A, Gómez J. Optimization methods applied to renewable and sustainable energy: A review. Renew Sustain Energy Rev 2011;15:1753-66. doi:10.1016/j.rser.2010.12.008.

[132] Sepúlveda M, Onetto E, Palma-Behnke R. Iterative Heuristic Response Surface Method for Transmission Expansion Planning. J Energy Eng 2007;133:69-77. doi:10.1061/(ASCE)0733-9402(2007)133:2(69).

[133] Iqbal M, Azam M, Naeem M, Khwaja AS, Anpalagan A. Optimization classification, algorithms and tools for renewable energy: A review. Renew Sustain Energy Rev 2014;39:640-54. doi:10.1016/j.rser.2014.07.120.

[134] Batas-Bjelic I, Skokljev I, Puksec T, Krajacic G, Duic N. Integrating the flexibility of the average Serbian consumer as a virtual storage option into the planning of energy systems. Therm Sci 2014;18:743-54. doi:10.2298/TSCI1403743B.

[135] Connolly D, Lund H, Mathiesen BV, Pican E, Leahy M. The technical and economic implications of integrating fluctuating renewable energy using energy storage. Renew Energy 2012;43:47-60. doi:10.1016/j.renene.2011.11.003.

[136] De Jonghe C, Delarue E, Belmans R, D'haeseleer W. Determining optimal electricity technology mix with high level of wind power penetration. Appl Energy 2011;88:2231-8. doi:10.1016/j.apenergy.2010.12.046.

[137] Dehghan S, Amjady N. Robust Transmission and Energy Storage Expansion Planning in Wind Farm-Integrated Power Systems Considering Transmission Switching. IEEE Trans Sustain Energy 2016;7:765-74. doi:10.1109/TSTE.2015.2497336.

[138] Denholm P, Sioshansi R. The value of compressed air energy storage with wind in transmission-constrained electric power systems. Energy Policy 2009;37:3149-58. doi:10.1016/j.enpol.2009.04.002.

[139] Erlenkotter D. Sequencing of interdependent hydroelectric projects. Water Resour Res 1973;9:21-7. doi:10.1029/WR009i001p00021.

[140] Fripp M. Switch: A Planning Tool for Power Systems with Large Shares of Intermittent Renewable Energy. Environ Sci Technol 2012;46:6371-8. doi:10.1021/es204645c

[141] Gagnon CR, Hicks RH, Jacoby SLS, Kowalik JS. A nonlinear programming approach to a very large hydroelectric system optimization. Math Program 1974;6:28-41. doi:10.1007/BF01580220.

[142] Garcia-Gonzalez J, de la Muela RMR, Santos LM, Gonzalez AM. Stochastic Joint Optimization of Wind Generation and Pumped-Storage Units in an Electricity Market. IEEE Trans Power Syst 2008;23:460-8. doi:10.1109/TPWRS.2008.919430.

[143] Good N, Karangelos E, Navarro-Espinosa A, Mancarella P. Optimization Under Uncertainty of Thermal Storage-Based Flexible Demand Response With Quantification of Residential Users’ Discomfort. IEEE Trans Smart Grid 2015;6:2333-42. doi:10.1109/TSG.2015.2399974.

[144] Greenblatt JB, Succar S, Denkenberger DC, Williams RH, Socolow RH. Baseload wind energy: modeling the competition between gas turbines and compressed air energy storage for supplemental generation. Energy Policy 2007;35:1474-92. doi:10.1016/j.enpol.2006.03.023.

[145] Gutiérrez-Martín F, Confente D, Guerra I. Management of variable electricity loads in wind - Hydrogen systems: The case of a Spanish wind farm. Int J Hydrogen Energy 2010;35:7329-36. doi:10.1016/j.ijhydene.2010.04.181.

[146] Heide D, von Bremen L, Greiner M, Hoffmann C, Speckmann M, Bofinger S. Seasonal optimal mix of wind and solar power in a future, highly renewable Europe. Renew Energy 2010;35:2483-9. doi:10.1016/j.renene.2010.03.012.

[147] Hreinsson EB. Optimal sizing of projects in a hydro-based power system. IEEE Trans Energy Convers 1990;5:32-8. doi:10.1109/60.50809.

[148] Ito K, Shiba T, Yokoyama R. Optimal capacity planning of thermal storage tanks installed into energy supply systems. Int J Glob Energy Issues 1997;9:162-70. doi:10.1504/IJGEI.1997.063332.

[149] Jaramillo O a., Borja M a., Huacuz JM. Using hydropower to complement wind energy: a hybrid system to provide firm power. Renew Energy 2004;29:1887-909. doi:10.1016/j.renene.2004.02.010.

[150] Kapsali M, Kaldellis JK. Combining hydro and variable wind power generation by means of pumped-storage under economically viable terms. Appl Energy 2010;87:3475-85. doi:10.1016/j.apenergy.2010.05.026.

[151] Kiviluoma J, Meibom P. Influence of wind power, plug-in electric vehicles, and heat storages on power system investments. Energy 2010;35:1244-55. doi:10.1016/j.energy.2009.11.004.

[152] Korpaas M, Holen AT, Hildrum R. Operation and sizing of energy storage for wind power plants in a market system. Int J Electr Power Energy Syst 2003;25:599-606. doi:10.1016/S0142-0615(03)00016-4.

[153] Krajačić G, Duić N, Zmijarević Z, Mathiesen BV, Vučinić AA, da Graça Carvalho M. Planning for a 100\% independent energy system based on smart energy storage for integration of renewables and CO2 emissions reduction. Appl Therm Eng 2011;31:2073-83. doi:10.1016/j.applthermaleng.2011.03.014.

[154] Meibom P, Kiviluoma J, Barth R, Brand H, Weber C, Larsen H V. Value of electric heat boilers and heat pumps for wind power integration. Wind Energy 2007;10:321-37. doi:10.1002/we.224.

[155] Novosel T, Ćosić B, Pukšec T, Krajačić G, Duić N, Mathiesen BV, et al. Integration of renewables and reverse osmosis desalination - Case study for the Jordanian energy system with a high share of wind and photovoltaics. Energy 2015;92:270-8. doi:10.1016/j.energy.2015.06.057.

[156] Obara S, Morizane Y, Morel J. Study on method of electricity and heat storage planning based on energy demand and tidal flow velocity forecasts for a tidal microgrid. Appl Energy 2013;111:358-73. doi:10.1016/j.apenergy.2013.05.018.

[157] Oh H. Optimal planning to include storage devices in power systems. IEEE Trans Power Syst 2011;26:1118-28. doi:10.1109/TPWRS.2010.2091515.

[158] Pagliarini G, Rainieri S. Modeling of a thermal energy storage system coupled with combined heat and power generation for the heating requirements of a University Campus. Appl Therm Eng 2010;30:1255-61. doi:10.1016/j.applthermaleng.2010.02.008.

[159] Papadaskalopoulos D, Strbac G, Mancarella P, Aunedi M, Stanojevic V. Decentralized Participation of Flexible Demand in Electricity Markets - Part II: Application With Electric Vehicles and Heat Pump Systems. IEEE Trans Power Syst 2013;28:3667-74. doi:10.1109/TPWRS.2013.2245687.

[160] Pellow M a, Emmott CJM, Barnhart CJ, Benson SM. Hydrogen or batteries for grid storage? A net energy analysis. Energy Environ Sci 2015;8:193852. doi:10.1039/C4EE04041D.

[161] Protogeropoulos C, Brinkworth BJ, Marshall RH. Sizing and techno-economical optimization for hybrid solar photovoltaic/wind power systems with battery storage. Fuel Energy Abstr 1997;38:167. doi:10.1016/S0140-6701(97)87994-5.

[162] Ramírez-Rosado IJ, García-Garrido E. Multi-objective Model for Optimal Integration of Dispersed Generation and Energy Storage Systems in Electric Power Distribution Networks Expansion. Adv. Mech. Electron. Eng., vol. 177, 2012, p. 497-504. doi:10.1007/978-3-642-31516-9_79.

[163] Saboori H, Hemmati R, Jirdehi MA. Reliability improvement in radial electrical distribution network by optimal planning of energy storage systems. Energy 2015;93:2299-312. doi:10.1016/j.energy.2015.10.125. 
[164] Schill W-P. Residual load, renewable surplus generation and storage requirements in Germany. Energy Policy 2014;73:65-79. doi:10.1016/j.enpol.2014.05.032.

[165] Shimizukawa J, Iba K, Hida Y, Yokoyama R, Tanaka K, Seki T. Best-Mix Generation Planning with Battery Energy Storage System Including CarbonNeutral Requirement. J Int Counc Electr Eng 2011;1:91-6. doi:10.5370/JICEE.2011.1.1.091.

[166] Sørensen B. A combined wind and hydro power system. Energy Policy 1981;9:51-5. doi:10.1016/0301-4215(81)90207-X.

[167] Steinke F, Wolfrum P, Hoffmann C. Grid vs. storage in a 100\% renewable Europe. Renew Energy 2013;50:826-32. doi:10.1016/j.renene.2012.07.044.

[168] Sullivan P, Short W, Blair N. Modeling the Benefits of Storage Technologies to Wind Power. Wind Eng 2008;32:603-15. doi:10.1260/030952408787548820.

[169] Swider DJ. Compressed Air Energy Storage in an Electricity System With Significant Wind Power Generation. IEEE Trans Energy Convers 2007;22:95102. doi:10.1109/TEC.2006.889547.

[170] Tedeschi E, Sjolte J, Molinas M, Santos M. Stochastic rating of storage systems in isolated networks with increasing wave energy penetration. Energies 2013;6:2481-500. doi:10.3390/en6052481.

[171] Tuohy A, O’Malley M. Pumped storage in systems with very high wind penetration. Energy Policy 2011;39:1965-74. doi:10.1016/j.enpol.2011.01.026.

[172] Weitemeyer S, Kleinhans D, Vogt T, Agert C. Integration of Renewable Energy Sources in future power systems: The role of storage. Renew Energy 2015;75:14-20. doi:10.1016/j.renene.2014.09.028.

[173] Xiong P, Singh C. Optimal Planning of Storage in Power Systems Integrated With Wind Power Generation 2015;7:1-9. doi:10.1109/TSTE.2015.2482939.

[174] Zerrahn A, Schill W-P. A Greenfield Model to Evaluate Long-Run Power Storage Requirements for High Shares of Renewables. SSRN Electron J 2015. doi:10.2139/ssrn.2591303.

[175] Zhang F, Hu Z, Song Y. Mixed-integer linear model for transmission expansion planning with line losses and energy storage systems. IET Gener Transm Distrib 2013;7:919-28. doi:10.1049/iet-gtd.2012.0666.

[176] Zhang N, Kang C, Kirschen DS, Xia Q, Xi W, Huang J, et al. Planning Pumped Storage Capacity for Wind Power Integration. IEEE Trans Sustain Energy 2013;4:393-401. doi:10.1109/TSTE.2012.2226067.

[177] Baxter R. Energy Storage: A Nontechnical Guide. 2006.

[178] Zhou Y, Mancarella P, Mutale J. Modelling and assessment of the contribution of demand response and electrical energy storage to adequacy of supply. Sustain Energy, Grids Networks 2015;3:12-23. doi:10.1016/j.segan.2015.06.001.

[179] Zhou Y, Mancarella P, Mutale J. A Framework for Capacity Credit Assessment of Electrical Energy Storage and Demand Response. IET Gener Transm Distrib 2016:1-17. doi:10.1049/iet-gtd.2015.0458.

[180] Althaher S, Mancarella P, Mutale J. Automated Demand Response From Home Energy Management System Under Dynamic Pricing and Power and Comfort Constraints. IEEE Trans Smart Grid 2015;6:1874-83. doi:10.1109/TSG.2014.2388357.

[181] Good N, Zhang L, Navarro-Espinosa A, Mancarella P. High resolution modelling of multi-energy domestic demand profiles. Appl Energy 2015;137:193-210. doi:10.1016/j.apenergy.2014.10.028.

[182] Galus MD, Koch S, Andersson G. Provision of Load Frequency Control by PHEVs, Controllable Loads, and a Cogeneration Unit. IEEE Trans Ind Electron 2011;58:4568-82. doi:10.1109/TIE.2011.2107715.

[183] Yakowitz S. Dynamic programming applications in water resources. Water Resour Res 1982;18:673-96. doi:10.1029/WR018i004p00673.

[184] Pazouki S, Haghifam M-R. Optimal planning and scheduling of energy hub in presence of wind, storage and demand response under uncertainty. Int J Electr Power Energy Syst 2016;80:219-39. doi:10.1016/j.ijepes.2016.01.044.

[185] Zhang L, Capuder T, Mancarella P. Unified Unit Commitment Formulation and Fast Multi-Service LP Model for Flexibility Evaluation in Sustainable Power Systems. IEEE Trans Sustain Energy 2016;7:658-71. doi:10.1109/TSTE.2015.2497411.

[186] Wollersheim O, Gutsch A. Transparenz ist gefragt (Transparency is required). Pv Mag 2015;2:53-7.

[187] Oshima T, Kajita M, Okuno A. Development of Sodium-Sulfur Batteries. Int J Appl Ceram Technol 2005;1:269-76. doi:10.1111/j.17447402.2004.tb00179.x.

[188] Finardi EC, Silva EL da, Sagastizábal C. Solving the unit commitment problem of hydropower plants via Lagrangian Relaxation and Sequential Quadratic Programming. Comput Appl Math 2005;24:317-41. doi:10.1590/S0101-82052005000300001.

[189] Chen H, Cong TN, Yang W, Tan C, Li Y, Ding Y. Progress in electrical energy storage system: A critical review. Prog Nat Sci 2009;19:291-312. doi:10.1016/j.pnsc.2008.07.014.

[190] Kousksou T, Bruel P, Jamil A, El Rhafiki T, Zeraouli Y. Energy storage: Applications and challenges. Sol Energy Mater Sol Cells 2013;120:59-80. doi:10.1016/j.solmat.2013.08.015.

[191] Divya KC, Østergaard J. Battery energy storage technology for power systems-An overview. Electr Power Syst Res 2009;79:511-20. doi:10.1016/j.epsr.2008.09.017.

[192] Martinez Romero S, Hughes W. Bringing variable renewable energy up to scale: options for grid integration using natural gas and energy storage. Washington D.C.: 2015

[193] Koohi-Kamali S, Tyagi VV, Rahim N a., Panwar NL, Mokhlis H. Emergence of energy storage technologies as the solution for reliable operation of smart power systems: A review. Renew Sustain Energy Rev 2013;25:135-65. doi:10.1016/j.rser.2013.03.056.

[194] Kurzweil P, Dietlmeier OK. Elektrochemische Speicher. Wiesbaden: Springer Vieweg; 2015. doi:10.1007/978-3-658-10900-4.

[195] Batlle C, Rodilla P. An Enhanced Screening Curves Method for Considering Thermal Cycling Operation Costs in Generation Expansion Planning. IEEE Trans Power Syst 2013;28:3683-91. doi:10.1109/TPWRS.2013.2249540.

[196] Geth F, Tant P, De Rybel T, Tant J, Driesen J. Techno-economical and life expectancy modeling of battery energy storage systems. 21st Int. Conf. Electr. Distrib., Frankfurt: 2011.

[197] TIMES 2014. http://www.iea-etsap.org/web/Times.asp (accessed July 2, 2014).

[198] Palmintier B, Webster M. Impact of unit commitment constraints on generation expansion planning with renewables. 2011 IEEE Power Energy Soc. Gen. Meet., IEEE; 2011, p. 1-7. doi:10.1109/PES.2011.6038963.

[199] Holttinen H. Impact of hourly wind power variations on the system operation in the Nordic countries. Wind Energy 2005;8:197-218. doi:10.1002/we. 143 .

[200] Ninghong Sun, Ellersdorfer I, Swider DJ. Model-based long-term electricity generation system planning under uncertainty. 3rd Int. Conf. Electr. Util. Deregul. Restruct. Power Technol., IEEE; 2008, p. 1298-304. doi:10.1109/DRPT.2008.4523607.

[201] Saint-Pierre A, Mancarella P. Active Distribution System Management: A Dual-Horizon Scheduling Framework for DSO/TSO Interface Under Uncertainty. IEEE Trans Smart Grid 2016:1-12. doi:10.1109/TSG.2016.2518084.

[202] Haas J, Olivares M a., Palma-Behnke R. Grid-wide subdaily hydrologic alteration under massive wind power penetration in Chile. J Environ Manage 2015;154:183-9. doi:10.1016/j.jenvman.2015.02.017.

[203] Olivares MA, Haas J, Palma-Behnke R, Benavides C. A framework to identify Pareto-efficient subdaily environmental flow constraints on hydropower reservoirs using a grid-wide power dispatch model. Water Resour Res 2015;51:3664-80. doi:10.1002/2014WR016215.

[204] Carpentier D, Haas J, Olivares M, Fuente A de la. Modeling the multi-seasonal link between the hydrodynamics of a reservoir and its hydropower plant operation. Water 2017; (accepted). doi:10.3390/w9060367.

[205] Petts GE. Impounded rivers, perspectives for ecological management. New York, NY: John Wiley \& Sons; 1984. 
[206] Scheidegger KJ, Bain MB. Larval Fish Distribution and Microhabitat Use in Free-Flowing and Regulated Rivers. Copeia 1995;1995:125. doi:10.2307/1446807.

[207] International Energy Agency. Energy Technology Perspectives 2014 - Harnessing Electricity’s Potential. Paris: 2014. doi:10.1787/energy_tech-2010en. 


\section{Caption of figures}

Fig. 1. Need for flexible power systems and flexibility sources

Fig. 2. Heat, transport, water and electricity sectorial coupling through ESS

Fig. 3. Time treatment of investment decisions: a) static optimization, b) milestone-years, c) rolling horizon, d) path optimization or dynamic optimization. Grey symbolizes share of fossil and green of renewable plants in time.

Fig. 4. Geographic evolution of SEP based on author affiliation of publications per decade. Orange: earlier than 1990, green: 1990s, light blue: 2000s, grey 2010s.

Fig. 5. Evolution of technologies considered in SEP per decade

Fig. 6. Evolution of SEP planning target per decade

Fig. 7. Evolution of cross-sectorial planning in SEP, including flexibility options within the power sector, over the last decades

Fig. 8. Detail of power system modeling in SEP in time

Fig. 9. Dynamic versus static formulations of investment decisions of SEP over time

Fig. 10. Time treatment of system operation in SEP over time

Fig. 11. Modeling of uncertainty in SEP over time

Fig. 12. Formulation of SEP problems over time 